Article

\title{
Fault Ride Through Capability Improvement of DFIG Based Wind Farm Using Nonlinear Controller Based Bridge-Type Flux Coupling Non-Superconducting Fault Current Limiter
}

\author{
Md. Rashidul Islam ${ }^{1, *}$, Md. Najmul Huda ${ }^{1}$, Jakir Hasan ${ }^{1}{ }^{10}$, \\ Mohammad Ashraf Hossain Sadi ${ }^{2}{ }^{\circ}$, Ahmed AbuHussein ${ }^{3}{ }^{\circ}$, Tushar Kanti Roy ${ }^{4}$ \\ and Md. Apel Mahmud ${ }^{4}$ (D) \\ 1 Department of Electrical \& Electronic Engineering, Rajshahi University of Engineering \& Technology, \\ Rajshahi 6204, Bangladesh; najmulhuda.ruet@gmail.com (M.N.H.); jakir.hasan@ieee.org (J.H.) \\ 2 College of Health, Science \& Technology, University of Central Missouri, Warrensburg, MO 64093, USA; \\ sadi@ucmo.edu \\ 3 Department of Electrical and Computer Engineering, Gannon University, Erie, PA 16541, USA; \\ abuhusse001@gannon.edu \\ 4 School of Engineering, Deakin University, Geelong, VIC 3216, Australia; t.roy@deakin.edu.au (T.K.R.); \\ apel.mahmud@deakin.edu.au (M.A.M.) \\ * Correspondence: rashidul@eee.ruet.ac.bd; Tel.: +880-1722261414
}

Received: 11 January 2020; Accepted: 25 February 2020; Published: 3 April 2020

\begin{abstract}
High penetration of Doubly Fed Induction Generator (DFIG) into existing power grid can attribute complex issues as they are very sensitive to the grid faults. In addition, Fault Ride Through (FRT) is one of the main requirements of the grid code for integrating Wind Farms (WFs) into the power grid. In this work, to enhance the FRT capability of the DFIG based WFs, a Bridge-Type Flux Coupling Non-Superconducting Fault Current Limiter (BFC-NSFCL) is proposed. The effectiveness of the proposed BFC-NSFCL is evaluated through performance comparison with that of the Bridge-Type Fault Current Limiter (BFCL) and Series Dynamic Braking Resistor (SDBR). Moreover, a dynamic nonlinear controller is also proposed for controlling the operation of the BFC-NSFCL. Extensive simulations are carried out in the MATLAB/SIMULINK environment for both symmetrical and unsymmetrical temporary as well as permanent faults. Based on the simulation results and different numerical analysis, it is found that the proposed nonlinear controller based BFC-NSFCL is very effective in enhancing the FRT capability of the WF. Also, the BFC-NSFCL outperforms the conventional BFCL and SDBR by maintaining a near-seamless performance during various grid fault situations.
\end{abstract}

Keywords: BFCL; BFC-NSFCL; DFIG; FRT; nonlinear controller; SDBR

\section{Introduction}

Fault Ride Through (FRT) capability augmentation of Doubly Fed Induction Generator (DFIG) based wind farms is a stability concern since the stability of the entire grid depends on it $[1,2]$. The stability requirements of every grid-connected distributed generators are defined by certain grid codes referred by the power system operators all around the world [3]. During a fault, a DFIG based wind farm must remain connected to the grid without exceeding certain voltage and frequency limits.

However, the sensitive nature of the DFIG based Wind Generators (WGs) to the grid faults have introduced numerous complexities and vulnerabilities for its stable operation. The transient over 
current due to fault can damage the Rotor Side Converter (RSC), Grid Side Converter (GSC) of the WG, and the DC-link. The Fault Ride Through (FRT) solutions provided in the literature [4-6] cannot fulfill all the grid code requirements as represented in Figure 1. But the application of FRT schemes with the WGs will help existing equipment to be in service by suppressing the transient over currents. Further, as the voltage sag during faults in the power grid is proportional to the fault current, effective FRT schemes connected with the WGs can also improve the FRT capability of the wind farms during fault.

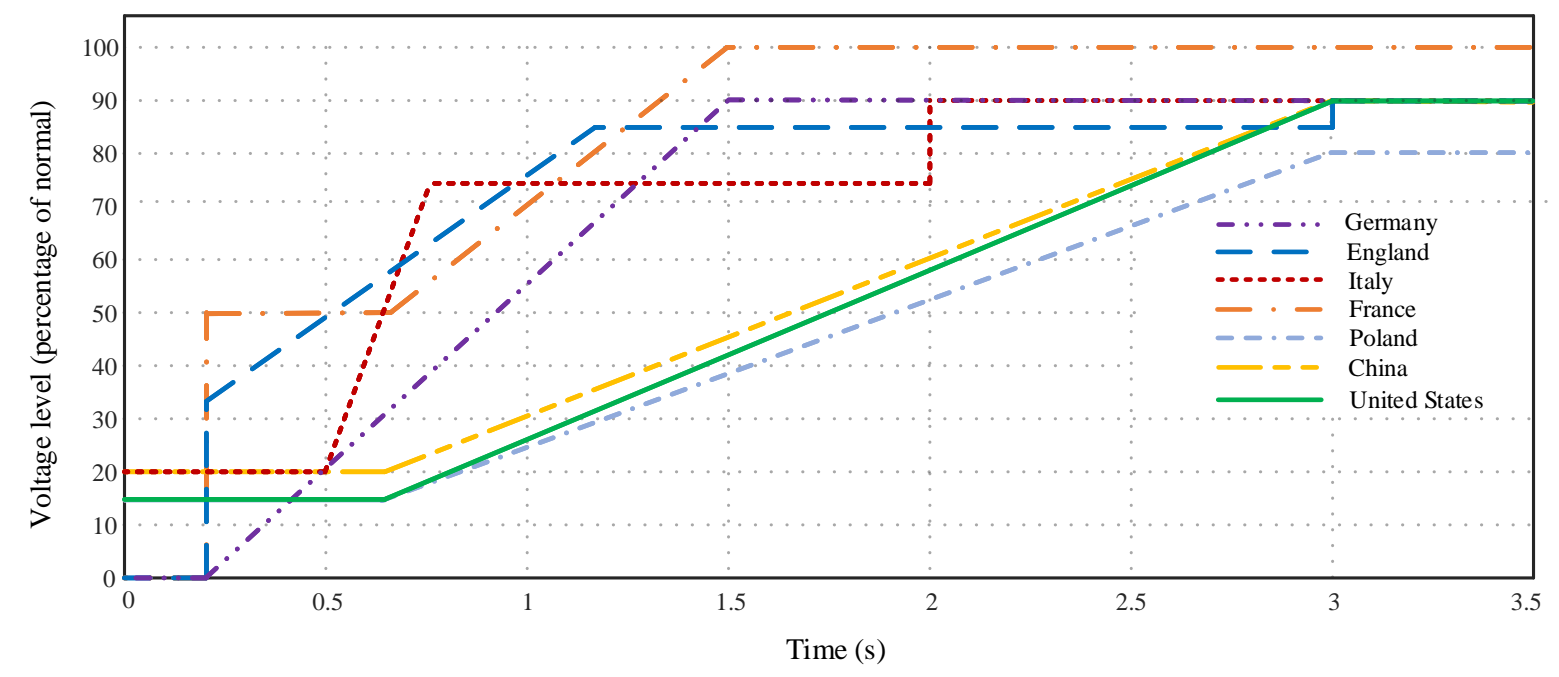

Figure 1. Grid code of different countries around the world.

There have been several proposals to improve the FRT capability of DFIG based wind farms. The use of crowbars is one of the oldest FRT schemes that offers resistance between the rotor and the rotor side converter (RSC) [7]. The problem of using crowbars is that they absorb reactive power from the grid during faults [8]. DC-link choppers are another popular FRT schemes to improve the FRT capability of DFIG based wind farms [6]. But the control approach of the DC-link choppers is complicated and also their performance is inferior to the crowbars [3]. The combining strategy of crowbars and DC-link choppers is then discussed in Reference [9] and then a comparative study between these two FRT schemes were carried out in Reference [8]. Some of the other conventional FRT schemes are Series Dynamic Resistors (SDRs) [10], Dynamic Voltage Restorer [5], STATCOM [11] and so forth. However, the performance of these FRT schemes is proven inferior to the Fault Current Limiters (FCLs) in every aspect [12-14].

Over the years, several types of FCLs have been proposed for the augmentation of FRT capability of power systems in numerous studies $[15,16]$. Each FCL has its advantages and disadvantages, and they demand specific environment to perform efficiently [17]. Vastly, the FCLs in DFIG based wind farms are divided into three categories that is, Superconducting Fault Current Limiters (SFCLs), Non-Superconducting Fault Current Limiters (NSFCLs) and Magnetic Fault Current Limiters (MFCLs) as shown in Figure 2.

The SFCLs have been extensively used in power system due to their excellent capability of minimizing fault current [18] but the use of SFCLs is fairly a recent addition in DFIG based wind farms [19]. The SFCLs offer a major advantage that the normal operation incurs no power loss. A cooperative control of SFCL and Superconducting Magnetic Energy Storage (SMES) system was introduced to ameliorate the energy management of the system during and after the fault [20]. Some of the other uses of SFCLs in DFIG based wind farms are discussed extensively in various papers [21,22]. However, the SFCLs are complex in structure, costly to implement and require liquid cryogenic system to change its mode from non-superconducting to superconducting. 


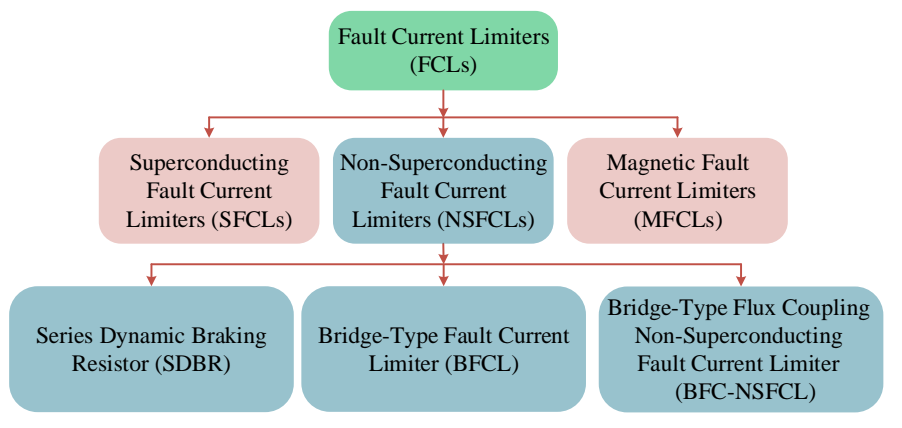

Figure 2. Classification of fault current limiters.

MFCLs are one of the finest FCLs to improve the transient stability of the system. Its basic configuration has a laminated core and a permanent magnet connecting the poles [23]. Permanent magnets are excellent in limiting fault current as they have large square hysteresis loop. Several applications of MFCLs are discussed in various papers [24,25]. But they have one major disadvantage that the permanent magnet of the MFCLs gets weak over time and so does the efficiency of the FCL.

On the other hand, the NSFCLs have reduced cost compared to the SFCLs while ensuring the same degree of dynamic stability [26]. Over the years, several NSFCLs have been proposed [12,27-34] but they are responsible for extensive power loss in the system due to their static components.

The use of flux coupling type SFCLs can minimize the power loss of the traditional FCLs significantly. But, as stated earlier, they have high cost and they induce certain problems in the system [17]. To overcome these limitations, in this paper, a Bridge-Type Flux Coupling Non-Superconducting Fault Current Limiter (BFC-NSFCL) is proposed to augment the FRT capability of DFIG based wind farms. This BFC-NSFCL has less utilization of Metal Oxide Varistor (MOV), use only one Insulated Gate Bipolar Transistor (IGBT) as a bridge switch, intentionally designed to ensure less current flow through the bridge switch to minimize the power loss and use electively the Circuit Breakers (CBs) in series with the BFC-NSFCL. To the best of our knowledge, the BFC-NSFCL has not been implemented yet in wind power generation systems regarding the improvement of FRT capability.

Further, there is a gap to be filled in the literature with an in-depth analysis and feasibility of nonlinearly controlled BFC-NSFCL. As the power system is highly nonlinear, a nonlinear controller would work better than a linear controller. The system can be linearized around certain equilibrium then the linear controller can stabilize the system, which will be more cost effective. However, it will be tough to capture the system dynamics as well as feedback errors in the controller when the system variables are uncertain [35,36]. Since the control scheme of BFC-NSFCL discussed in Reference [26] lacks proper feedback signals, some degree of tracking errors, as well as steady-state errors, are imminent.

Based on these backgrounds, this paper presents a nonlinear controller to control the operation of the BFC-NSFCL, which is another salient feature of this work. Moreover, to evaluate the efficacy of the nonlinear controller based BFC-NSFCL, its performances are compared with other prominent FCLs such as the Series Dynamic Braking Resistor (SDBR) [33,34] and Bridge-Type Fault Current Limiter (BFCL) [27,28].

\section{Modeling of DFIG}

To understand the dynamics of the whole system, three types of modeling are discussed here. The models are provided in the following subsections. 


\subsection{Wind Power Modeling}

The power extracted from the wind can be represented by the following expression $[27,31,37,38]$,

$$
P_{\omega}=\frac{1}{2} \pi \rho R^{2} V_{\omega}^{3} C_{p}(\lambda, \beta),
$$

where $\rho$ is the air density, $R$ is the rotor blade radius, $V_{\omega}$ is the wind velocity, $C_{p}$ is the performance coefficient, $\lambda$ is the tip speed ratio and $\beta$ is the blade pitch angle. $C_{p}$ can be further expressed as,

$$
\begin{gathered}
C_{p}(\lambda, \beta)=\frac{1}{2}\left(\lambda-0.022 \beta^{2}-5.6\right) e^{-0.17 \lambda} \\
\lambda=\frac{\omega_{r} R}{V_{\omega}},
\end{gathered}
$$

where $\omega_{r}$ denotes mechanical angular velocity of the blade.

\subsection{Modeling of DFIG Under Normal Condition}

For modeling of DFIG, Park's model [39] is very useful and widely used and the model has a stator oriented frame of reference. The reference frame is specially generated for DFIG and is very useful for analyzing the responses of DFIG under normal and fault conditions. The $a b c$ frame of the stator and rotor voltages are stated using motor convention by the following expressions [3,36,39],

$$
\begin{gathered}
\vec{u}_{s}=R_{s} \overrightarrow{i_{s}}+\frac{d}{d t} \overrightarrow{\lambda_{s}} \\
\overrightarrow{u_{r}}=R_{r} \overrightarrow{i_{r}}+\frac{d}{d t} \overrightarrow{\lambda_{r}}-j \omega_{m} \vec{\lambda}_{r}
\end{gathered}
$$

The fluxes induced in the stator and rotor can be expressed as,

$$
\begin{aligned}
& \overrightarrow{\lambda_{s}}=L_{s} \overrightarrow{i_{s}}+L_{m} \overrightarrow{i_{r}} \\
& \overrightarrow{\lambda_{r}}=L_{r} \overrightarrow{i_{r}}+L_{m} \overrightarrow{i_{s}},
\end{aligned}
$$

where $\overrightarrow{u_{s}}$ and $\overrightarrow{u_{r}}$ are the space vector of the stator and rotor voltages respectively, $\overrightarrow{i_{s}}$ and $\overrightarrow{i_{r}}$ are the space vector of the stator and rotor currents respectively, $R_{s}$ and $R_{r}$ are the stator and rotor resistances respectively, $L_{m}$ is the magnetizing inductance, $\vec{\lambda}_{s}$ and $\vec{\lambda}_{r}$ are the space vector of the stator and rotor fluxes respectively and $\omega_{m}$ is the slip angular frequency. $L_{s}$ and $L_{r}$ can be further expressed by the following expressions,

$$
\begin{aligned}
& L_{s}=L_{l s}+L_{m} \\
& L_{r}=L_{l r}+L_{m} .
\end{aligned}
$$

where $L_{S}$ and $L_{r}$ are the leakage inductances of the stator and rotor respectively. Figure 3 clearly illustrates the construction of (8) and (9).

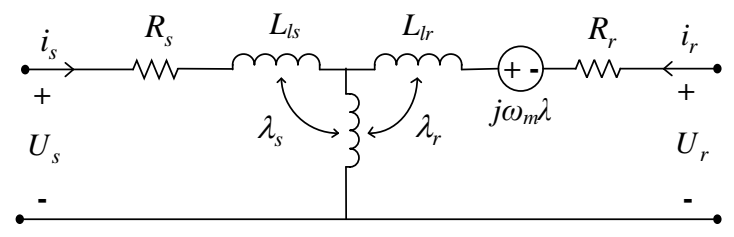

Figure 3. Equivalent circuit of Doubly Fed Induction Generator (DFIG). 
Manipulating (6) and (7), we obtain,

$$
\overrightarrow{\lambda_{r}}=\frac{L_{m}}{L_{s}} \overrightarrow{\lambda_{s}}-\sigma L_{r} \vec{i}_{r}
$$

where

$$
\sigma=1-\frac{L_{m}^{2}}{L_{s} L_{m}} .
$$

Substituting the value of $\vec{\lambda}_{r}$ into (6) and with some further adjustments, we obtain,

$$
\vec{u}_{r}=\frac{L_{m}}{L_{s}}\left(\frac{d}{d t}-j \omega_{m}\right) \vec{\lambda}_{s}+\left(R_{r}+\sigma L_{r}\left(\frac{d}{d t}-j \omega_{m}\right)\right) \vec{i}_{r} .
$$

We can obtain the rotor open circuit voltage $\overrightarrow{u_{r 0}}$ by putting $\overrightarrow{i_{r}}=0$ in (12),

$$
\overrightarrow{u_{r 0}}=\frac{L_{m}}{L_{s}}\left(\frac{d}{d t}-j \omega_{m}\right) \overrightarrow{\lambda_{s}} .
$$

Now, since the transient reactance and the rotor resistance are both negligible, the right hand side of (12) is smaller compared to $\overrightarrow{u_{r 0}}$. So, we can write $\overrightarrow{u_{r 0}}$ as,

$$
\overrightarrow{u_{r 0}}=j \omega_{r} \frac{L_{m}}{L_{s}} \overrightarrow{\lambda_{s}}=\frac{L_{m}}{L_{s}} \frac{\omega_{r}}{\omega_{s}} U_{s} e^{j \omega_{s} t},
$$

where $\omega_{r}$ and $\omega_{s}$ are the synchronous and angular frequencies of slip respectively. The magnitude of $\overrightarrow{u_{r 0}}$ can be found as,

$$
U_{r 0}=\frac{L_{m}}{L_{s}} \frac{\omega_{r}}{\omega_{s}} U_{s}=\frac{L_{m}}{L_{s}} s U_{s}
$$

where $s$ is the slip which can be expressed as,

$$
\begin{gathered}
s=\frac{\omega_{s}-\omega_{m}}{\omega_{s}} \\
\omega_{r}=\omega_{s}-\omega_{m} .
\end{gathered}
$$

So, it is clear from (15) that the rotor voltage has a proportional relation with the stator voltage and the slip.

\subsection{Modeling of DFIG Under Fault}

The open circuit voltage experiences a drastic change at the fault instant. This changed voltage is expressed as $[3,36,39]$,

$$
\overrightarrow{u_{r 0}}=-\frac{L_{m}}{L_{s}}\left(j \omega_{m}+\frac{1}{\tau_{s}}\right) \frac{U_{s}}{j \omega_{s}} e^{j \omega_{s} t_{0}} e^{-\frac{t}{\tau_{s}}}
$$

This open circuit voltage rotates in the opposite direction at an angular frequency of $\omega_{m}$ and this rotating voltage can be expressed as,

$$
\overrightarrow{u_{r 0}^{r}}=-\frac{L_{m}}{L_{s}}\left(j \omega_{m}+\frac{1}{\tau_{s}}\right) \frac{U_{s}}{j \omega_{s}} e^{j \omega_{s} t_{0}} e^{j \omega_{m} t} e^{-\frac{t}{\tau_{s}}} .
$$

Obviously $\left|\overrightarrow{u_{r 0}^{r}}\right|$ reaches its peak during fault. Since $\frac{1}{\tau_{s}}$ is very small and (19) can be written as,

$$
U_{r 0}\left(t_{0}\right)=\frac{L_{m}}{L_{s}} \frac{\omega_{m}}{\omega_{s}} U_{s}=\frac{L_{m}}{L_{s}}(1-s) U_{s}
$$


Hence, the open circuit rotor voltage is proportional to $(1-s)$ during fault but during normal condition, it is proportional to $s$ as seen from (15).

\section{System Model}

In this work, a 9 MVA wind farm consisting of six wind turbines and six DFIGs rated at 1.5 MVA each, are used as represented in Figure 4. The rotor side of each DFIG is interfaced with a Rotor Side Converter (RSC). The RSC is then linked with the Grid Side Converter (GSC) via a DC-link capacitor. The output of each DFIG is stepped up to $66 \mathrm{KV}$ for efficient transmission. Finally, the output of all six DFIGs are supplied to the parallel transmission lines which help to provide reliable transmission of power. The parallel transmission lines are modeled with line impedance and circuit breakers. The BFC-NSFCL is placed between the Point of Common Coupling (PCC) and the parallel transmission lines. All the DFIGs used in the system have identical rating. The parameters of a DFIG are shown in Table A1. The discussions about RSC and GSC are provided in the following sub-sections.

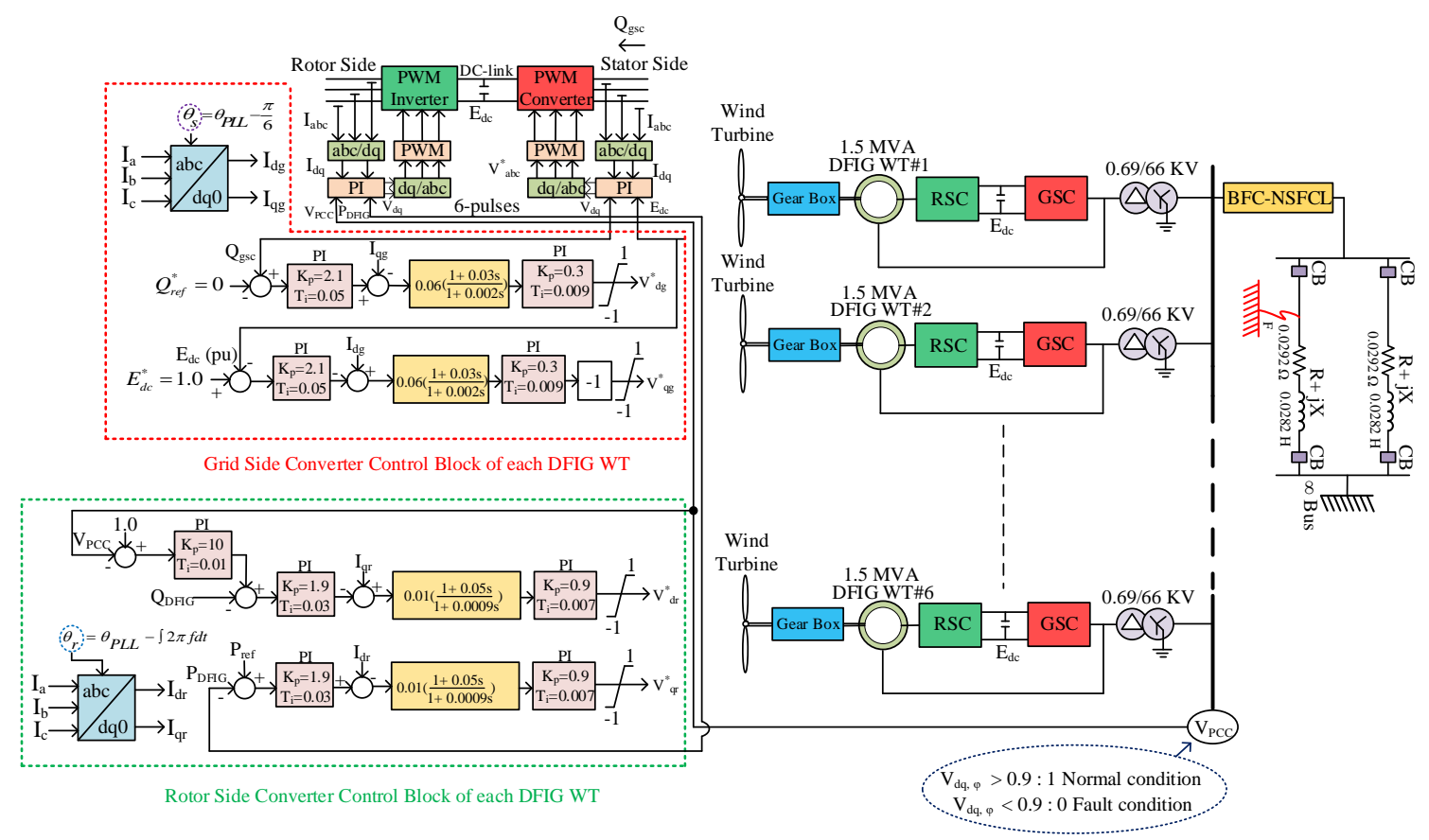

Figure 4. Diagram of the study system.

\subsection{RSC Controller}

The RSC is mainly an IGBT based full bridge, six pulse, two level power converter that interfaces the rotor side with the DC-link. It regulates the PCC voltage $V_{P C C}$ to $1.0 \mathrm{pu}$. The $d$-axis and the $q$-axis currents control the active power and the reactive power respectively. The $a b c$ voltage is converted to the $d q$ voltage and vice versa by using Park's transformation, after that $V_{d r}^{*}$ and $V_{q r}^{*}$ are transmitted to the Pulse Width Modulation (PWM) signal generator. This PWM block eventually generates pulses for the IGBT switches of RSC by using the effective angle $\theta_{r}$ [38].

\subsection{GSC Controller}

The GSC is also a power electronic converter which is IGBT based full bridge, six pulse, two level with the AC side connected to the grid and the DC side interfaced to the DC-link capacitor. Here $\theta_{P L L}$ is provided by the Phase Locked Loop (PLL) and $\theta_{S}$ is the effective angle for the $a b c$-to- $d q$ transformation and vice versa. The GSC is used mainly to control the DC-link voltage $\left(E_{d c}\right)$ to $1.0 \mathrm{pu}$. The DC-link voltage is regulated by $d$-axis current, while the reactive power of GSC is regulated by $q$-axis current. After a $d q$-to-abc conversion, $V_{d g}^{*}$ and $V_{q g}^{*}$ are transmitted to the PWM signal generator 
of GSC. The chosen switching frequency of the converter is $1650 \mathrm{~Hz}$ due to two reasons, that is, it offers odd multiple of the third harmonic and it can reduce up to thirteenth harmonics. The DC-link voltage is maintained to a constant value so that the controller provides energy balance on either side of the DC-link. The DC-link is actually a power capacitor of $12,000 \mu \mathrm{F}$ which is mainly used to eliminate the DC ripple voltage and maintain it to a fixed value of $1200 \mathrm{~V}$. The values of transfer function and PI controller of Figure 4 are taken from Reference [38].

\section{Bridge-Type Flux Coupling Non-Superconducting Fault Current Limiter (BFC-NSFCL)}

\subsection{Construction}

The proposed BFC-NSFCL configuration is shown in Figure 5. The proposed fault current limiter has mainly two parts, that is, the Flux Coupling Reactor (FCR) and the bidirectional bridge switch. The FCR has two coils of separate turns. The bidirectional bridge switch mainly consists of a diode bridge rectifier circuit, an IGBT, a MOV and a RC snubber. The bridge switch is in the secondary coil of the FCR which has a vital role in normal operation in making the two coils magnetically coupled. The diode bridge rectifier holds higher reliability because it is a passive component. The switch can be easily implemented on the high-voltage power system, which is another significant advantage of this topology [26].

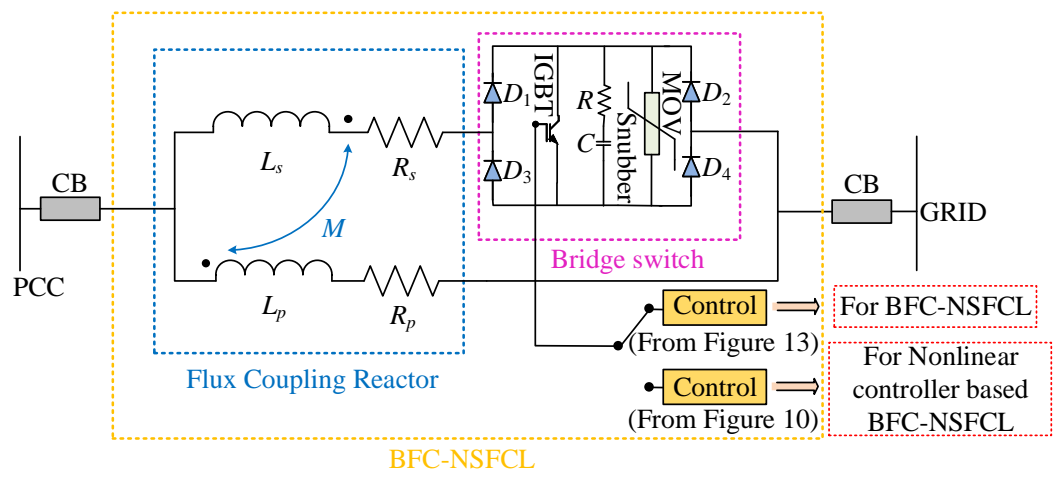

Figure 5. Per phase configuration of the proposed Bridge-Type Flux Coupling Non-Superconducting Fault Current Limiter (BFC-NSFCL).

The MOV and RC snubber is used to eradicate the transient over-voltage that is caused by changing of the IGBT state. As soon as a fault occurs in the line, the secondary coil current of the FCR should be terminated as soon as possible but practically, the separation of the secondary coil cannot be done instantaneously. As a result, often a transient over-voltage appears at the terminal of the bridge switch. To avoid vandalism of the diode bridge rectifier and the IGBT, a RC snubber is placed in parallel connection with the output connection point of the rectifier. Moreover, it provides protection against the instantaneous change of voltage.

\subsection{Working Principle}

The basic working principle of BFC-NSFCL can be classified into two distinctive states. Brief discussions about each of these states are provided in the following subsections.

\subsubsection{Normal State}

The line current flows separately along the primary and secondary winding of the FCR. The line current during the positive half cycle flows through the path $D_{1}-I G B T-D_{4}$, that is, red indicated path in Figure 6a. In negative half cycle, current goes through $D_{3}-I G B T-D_{2}$ as shown by the red indicated path in Figure 6b. The alignment of the two windings of the BFC-NSFCL are reverse and concentric. So, the fluxes of primary and secondary coils of the FCR counteract each other. Since it offers zero 
impedance in this condition, the voltage across BFC-NSFCL is negligible. As a result, there is no significant influence of BFC-NSFCL in normal operating condition. The number of turns of the primary side is kept less compared to the secondary side to make sure that the bridge switch carries less line current. This specific design ensures current sharing function and so the power loss across the bridge switch is minimized.

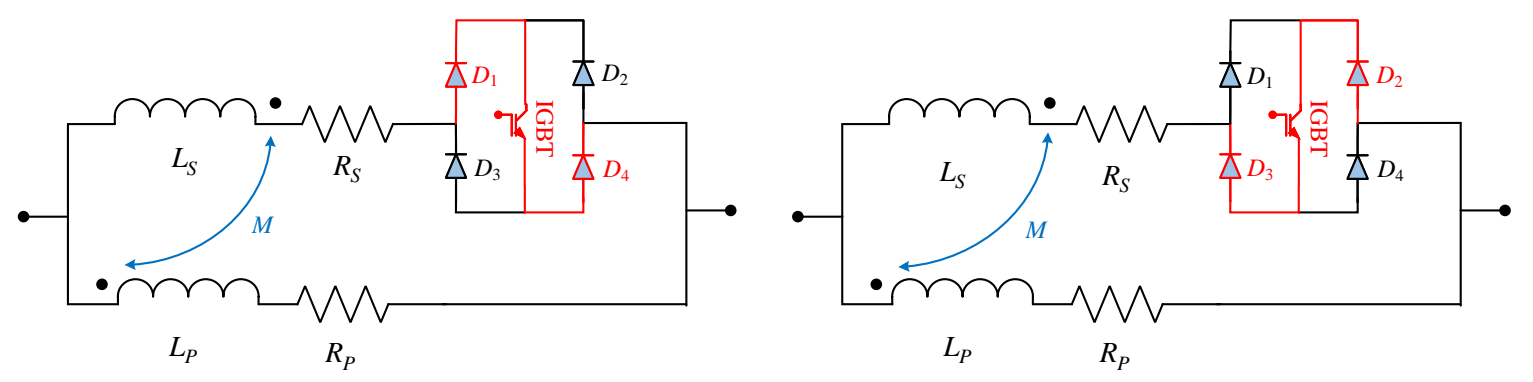

(a)

(b)

Figure 6. Per phase BFC-NSFCL configuration during normal period: (a) For positive half cycle; (b) For negative half cycle.

\subsubsection{Fault State}

During the event of a fault, the control circuit and other sensing unit senses the fault. The control circuit makes the bridge switch turned off. Then the secondary of the FCR gets detached from the system and the entire fault current flows through the only path available, the primary coil. The working principle of the BFC-NSFCL during a fault is shown in Figure 7. Since the primary coil is the only path that carries the fault current, its impedance is designed in a way that it can restrain the fault current to an expected value $\left(I_{\text {expected }}\right)$ and maintain an acceptable level of grid voltage. When the fault is cleared, the BFC-NSFCL recovers to its initial state and be ready for the occurrence of another fault.

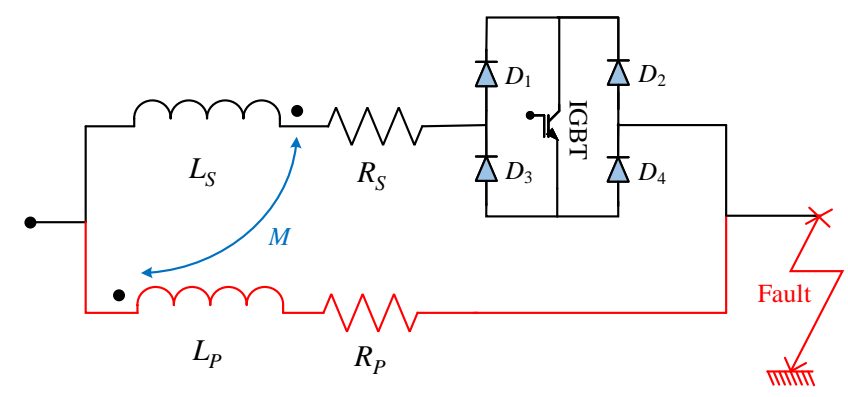

Figure 7. Per phase BFC-NSFCL configuration during fault period.

\subsection{Theoretical Design Considerations}

To understand the counter effect of the FCR, the fundamentals of magnetically coupled circuit needs to be discussed first. When two loops regardless of whether they have contacts between them or not, have influence on each other through magnetic field generated by one of them, they are said to be magnetically coupled. When two current carrying inductors $\left(L_{1}\right.$ and $\left.L_{2}\right)$ are in a close proximity to each other, they induce certain amount of voltage on each other defined as the mutual inductance (M). The polarity of this mutual voltage can be determined using the dot convention as depicted in Figure 8. According to dot convention, the equivalent inductance for series-aiding connection is,

$$
L_{e q}=L_{1}+L_{2}+2 M
$$


and for series opposing connection, $L_{e q}$ can be written as,

$$
L_{e q}=L_{1}+L_{2}-2 M \text {. }
$$

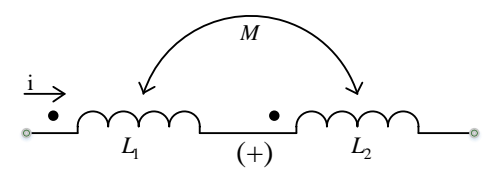

Series-aiding connection

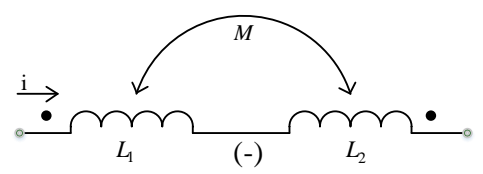

Series-opposing connection

Figure 8. Equivalent inductance of series-aiding and series-opposing connection.

To perform theoretical analysis, a single-phase AC circuit can be demonstrated in Figure 9. Its normal and fault states are discussed in the following subsections.

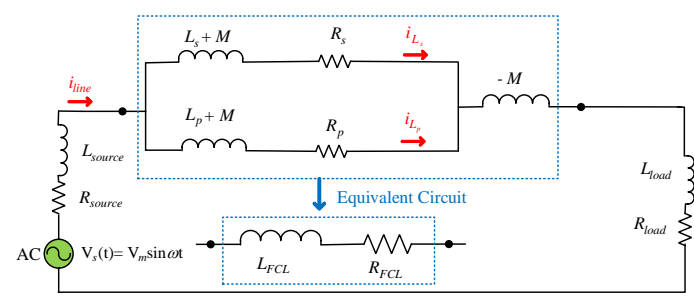

(a)

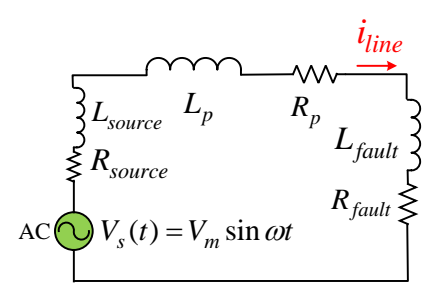

(b)

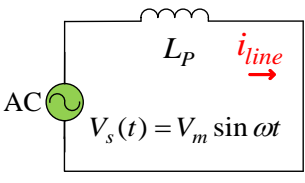

(c)

Figure 9. Equivalent circuit for theoretical analysis: (a) During normal operation; (b) During fault; (c) Simplified equivalent circuit during fault.

\subsubsection{Normal State}

The magnitude of line current is too small in this state. Hence, the voltage drop across the bridge switch is considered negligible for the simplicity of analysis. The primary and secondary coils are coupled magnetically and the equivalent circuit of the normal condition is depicted in Figure 9a. The equivalent impedance of the fault current limiter can be expressed as [26],

$$
\begin{aligned}
Z_{F C L}= & R_{F C L}+j \omega L_{F C L} \\
& =\frac{\left(R_{p}+R_{s}\right)\left[R_{p} R_{s}+\omega^{2}\left(M^{2}-L_{p} L_{s}\right)\right]}{\left(R_{p}+R_{s}\right)^{2}+\omega^{2}\left(L_{p}+L_{s}+2 M\right)^{2}}+\frac{\omega^{2}\left(L_{p} R_{s}+L_{s} R_{p}\right)\left(L_{p}+L_{s}+2 M\right)}{\left(R_{p}+R_{s}\right)^{2}+\omega^{2}\left(L_{p}+L_{s}+2 M\right)^{2}} \\
& +j \omega\left[\frac{\left[\left(R_{p}+R_{s}\right)\left(L_{p} R_{s}+L_{s} R_{p}\right)\right]}{\left(R_{p}+R_{s}\right)^{2}+\omega^{2}\left(L_{p}+L_{s}+2 M\right)^{2}}-\frac{\left(L_{p}+L_{s}+2 M\right)\left[R_{p} R_{s}+\omega^{2}\left(M^{2}-L_{p} L_{s}\right)\right]}{\left(R_{p}+R_{s}\right)^{2}+\omega^{2}\left(L_{p}+L_{s}+2 M\right)^{2}}\right],
\end{aligned}
$$

where

$L_{p}=$ Primary coil inductance of the FCR

$L_{s}=$ Secondary coil inductance of the FCR

$R_{p}=$ Primary coil resistance of the FCR

$R_{S}=$ Secondary coil resistance of the FCR

$M=$ Mutual inductance of the primary and secondary coils of the FCR

Applying KVL in the circuit shown in Figure 9a, we obtain,

$$
V_{m} \sin \omega t=\left(L_{\text {source }}+L_{F C L}+L_{\text {load }}\right) \frac{d i_{\text {line }}(t)}{d t}+\left(R_{\text {source }}+R_{F C L}+R_{\text {load }}\right) i_{\text {line }}(t)
$$


Solving (24) we get,

$$
i_{\text {line }}=\frac{V_{m}}{Z_{T}} \sin \left(\omega t-\theta_{Z}\right),
$$

where,

$$
\begin{gathered}
Z_{T}=\sqrt{\left(R_{\text {source }}+R_{F C L}+R_{\text {load }}\right)^{2}+\omega^{2}\left(L_{\text {source }}+L_{F C L}+L_{\text {load }}\right)^{2}} \\
\theta_{Z}=\tan ^{-1}\left[\frac{\omega\left(L_{\text {source }}+L_{F C L}+L_{\text {load }}\right)}{\left(R_{\text {source }}+R_{F C L}+R_{\text {load }}\right)}\right]
\end{gathered}
$$

where $R_{\text {source }}$ and $R_{\text {load }}$ are the resistances of voltage source and load respectively, $L_{\text {source }}$ and $L_{\text {load }}$ are the inductances of voltage source and load respectively.

\subsubsection{Fault State}

During fault, the IGBT switch is turned OFF and the primary impedance suppresses the fault current. However, the occurrence of fault and the operation of IGBT switch comprises of two substates:

\section{Transient substate:}

This is the time between the occurrence of the fault and the switching of the IGBT. When the fault occurs in the system, the PCC voltage gets low drastically. When the voltage goes as low as the threshold value $\left(V_{t h}\right)$, the control scheme gets activated and the IGBT switch goes OFF. But until the voltage reaches $V_{t h}$, the fault current is too small to trigger the IGBT. So, during this period, the IGBT remains ON and the load impedance is replaced by the impedance of the fault path. However, the magnitude of the line current is so small during this transition substate and it can be ignored for the simplicity of analysis [26].

Suppressive substate:

This is the time period after the IGBT is switched OFF. During the suppressive substate, the PCC voltage becomes low enough and the bridge switch turns OFF because the control scheme sends zero signal to the IGBT. During this period, only the primary winding remains in the circuit and the load becomes short circuited so the impedance of the fault path replaces the impedance of the load. Applying KVL to Figure 9b, the circuit voltage during fault can be written as,

$$
V_{m} \sin \omega t=L \frac{d i_{\text {line }}}{d t}+R i_{\text {line }},
$$

where $L=L_{\text {source }}+L_{p}+L_{\text {fault }}$ and $R=R_{\text {source }}+R_{p}+R_{\text {fault }}$. For theoretical analysis, the parameters of the system are considered to be ideal so that the resistances and inductances of the source, fault path and resistance of the primary coil all are assumed to be zero $\left(R_{\text {source }}=R_{p}=R_{\text {fault }}=L_{\text {source }}=L_{\text {fault }}\right.$ $=0$ ). From the Figure $9 c$, it can be written as,

$$
V_{m} \sin \omega t=L_{p} \frac{d i_{\text {line }}}{d t} .
$$

Since the main purpose of the primary inductance of the FCR is to limit the magnitude of $i_{\text {line }}$ to the expected fault current value, $I_{\text {expected }}$, the approximate value of the primary coil inductance can be calculated as,

$$
L_{p}=\frac{2 V_{m}}{\omega I_{\text {expected }}} .
$$

The value of $L_{s}$ is chosen greater than $L_{p}$ as stated earlier to reduce the bridge switch power loss. This value of $L_{s}$ is chosen in a way that $M=K \sqrt{L_{p} L_{s}}$ creates a counter-effect of resultant flux in normal condition, where $K$ is called the coupling coefficient. The values of $R_{p}$ and $R_{S}$ are taken from Reference [26]. The parameters of BFC-NSFCL are shown in Table 1. 
Table 1. Parameters of the BFC-NSFCL.

\begin{tabular}{cccccc}
\hline $\boldsymbol{R}_{\boldsymbol{p}}$ & $\boldsymbol{L}_{\boldsymbol{p}}$ & $\boldsymbol{R}_{\boldsymbol{s}}$ & $\boldsymbol{L}_{\boldsymbol{s}}$ & $\boldsymbol{M}$ & $\boldsymbol{K}$ \\
\hline $1.56 \Omega$ & $250 \mathrm{mH}$ & $0.21 \Omega$ & $350 \mathrm{mH}$ & $292.84 \mathrm{mH}$ & 0.99 \\
\hline
\end{tabular}

\subsection{Proposed Nonlinear Controller for the BFC-NSFCL}

The BFC-NSFCL alone works fine to ameliorate the transient stability of the system. However, the efficiency of the BFC-NSFCL can be increased to some extent by using a controller to control the BFC-NSFCL. Since the power system is extremely nonlinear in character, here, an exponential nonlinear controller is proposed. The proposed nonlinear controller for the BFC-NSFCL is simple and has the advantage of exploiting a less complicated nonlinear controller for easy implementation. Unlike other nonlinear controllers, it doesn't need any prior training and incorporates the severity of the fault in the controller's design process through the duty ratio, $d$ generated from the PWM block of the controller. Thus, the proposed exponential nonlinear controller introduces variable limiting effect based on the system dynamics and that is the motivation behind utilizing it than other nonlinear controllers available in the literature $[12,13,28,40,41]$. The schematic diagram of the controller is illustrated in Figure 10. The instantaneous voltage near the PCC is converted to direct $\left(V_{d, \phi}\right)$ and quadrature $\left(V_{q, \phi}\right)$ counterparts, which eventually produces $V_{d q, \phi}$.

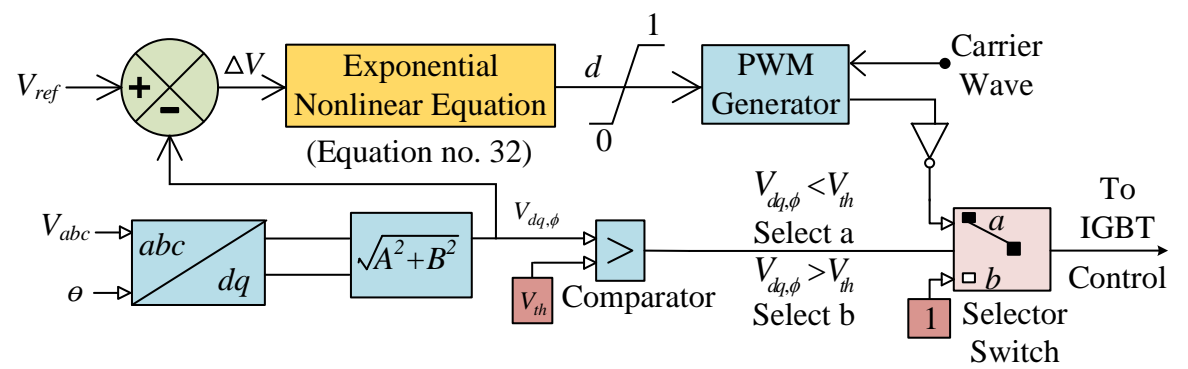

Figure 10. Gate control of Insulated Gate Bipolar Transistor (IGBT) for nonlinear controller based BFC-NSFCL.

This instantaneous $d q$ voltage, $V_{d q, \phi}$ is compared with a reference level of the voltage, $V_{r e f}$. The difference between the $V_{d q, \phi}$ and $V_{r e f}, \Delta V$ is supplied to the exponential nonlinear control block in order to produce the duty ratio, $d$ and it passes through the saturation block and then the PWM generator block. The equation of $d$ can be written as [36],

$$
d=\frac{T_{o f f}}{T_{c}}
$$

where $T_{\mathcal{C}}$ is the time period of the carrier wave, $T_{o f f}$ is the time at which IGBT of the BFC-NSFCL does not conduct. The instantaneous level of $V_{d q, \phi}$ can detect the fault more quickly and precisely. The value of the $V_{d q, \phi}$ is compared to a threshold voltage level, $V_{t h}(0.9 \mathrm{pu})$ for the detection of any fault in the system. The output of this comparator is fed to a switch selector that can select either 1 or inverted output of the PWM generator and supply it to the gate of IGBT. During normal operating condition $\left(V_{d q, \phi}>V_{t h}\right)$, the selector output is 1 and so the IGBT is in conduction. During fault $\left(V_{d q, \phi}<V_{t h}\right)$, the selector selects the inverted PWM generator output and sends it to the IGBT gate. But, instead of applying the full impedance of primary path during the entire fault period, a variable effective primary impedance $Z_{p r}^{*}=d \times Z_{p r}$ is provided to the system model for flexible compensation by the BFC-NSFCL, where $Z_{p r}$ denotes the primary path impedance. The magnitude of $\Delta V$ is the direct indication of fault severity as it is higher for more severe fault and vice versa. The effective variable impedance of the primary coil, $Z_{p r}^{*}$ depends directly on $d$ which is eventually dependent on $\Delta V$ regulated by the following nonlinear equation, 


$$
d=1-e^{-C \Delta V}
$$

where $C$ is a constant and $d$ is the duty ratio dependent on different values $\Delta V$ during symmetrical and unsymmetrical faults. The response of (32) for different values of $C$ are shown in Figure 11a. The performance indices of the PCC voltage during a temporary 3LG fault defined by the equation $v l t(p u . s)=\int_{0}^{T}|\Delta V| d t$ are also measured for different values of $C$. It is found that $C=15$ provides the best performance in our system model for all types of faults. Overcompensation occurs for values greater than 15 and for values less than 15, inadequate compensation is observed. The values of percentage $v l t(p u . s)$ for different values of $C$ are shown in Figure 11b. As it can be seen from Figure $11 \mathrm{~b}$, for the values from 5 to 12, the indices are the largest. The percentage index begins to decrease from $C=13$ and it keeps on decreasing till 15. For $C=15$, the value of percentage $v l t(p u . s)$ is the lowest. After that, the value starts to increase again and from $C=21$, the values remained constant for every value greater than 21 .

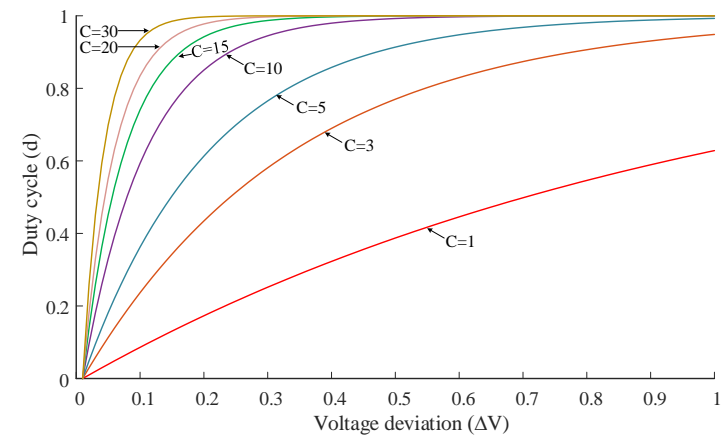

(a)

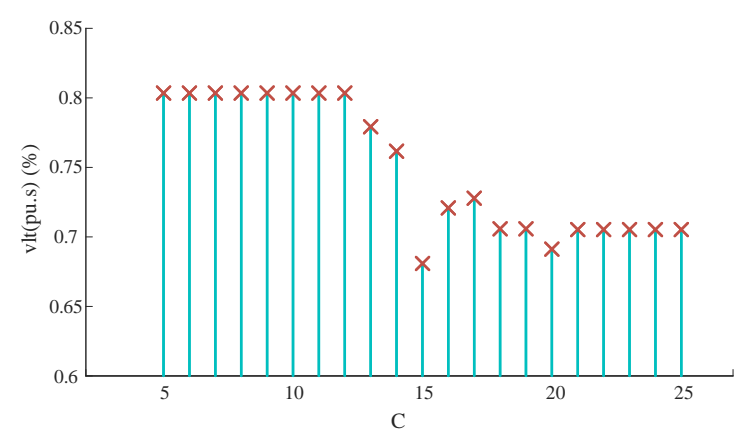

(b)

Figure 11. Influence of $C$ on duty cycle and percentage indices: (a) Relation between duty cycle and voltage deviation for different values of $C$; (b) Percentage index of voltage deviation for different values of C.

\section{Bridge-Type Fault Current Limiter (BFCL) and Series Dynamic Braking Resistor (SDBR)}

The performance of the proposed nonlinear controller based BFC-NSFCL has been compared and analyzed with that of the BFCL and the SDBR. Their constructions and control structures are discussed in the subsections below.

\subsection{Construction of the BFCL}

The BFCL was first introduced in DFIG based wind farms in Reference [27] and has been used successfully since then. The BFCL consists of two distinctive parts as represented in Figure 12 . The main part of the BFCL is a typical bridge circuit with four diodes $\left(D_{1}-D_{4}\right)$. The other part is a shunt path consisting of an inductor $\left(L_{s h}\right)$ and a resistor $\left(R_{s h}\right)$ in series. Inside the bridge, there is an IGBT switch in series with an inductor $\left(L_{d c}\right)$. Here $R_{d c}$ is the intrinsic resistance of $L_{d c}$ with very negligible magnitude. This inductor $L_{d c}$ works as a DC reactor because current flows unidirectionally through it during both positive and negative half cycle of AC current. The DC reactor $\left(L_{d c}\right)$ comes with a free-wheeling diode $\left(D_{5}\right)$ to protect it from inductive kick during fault. 


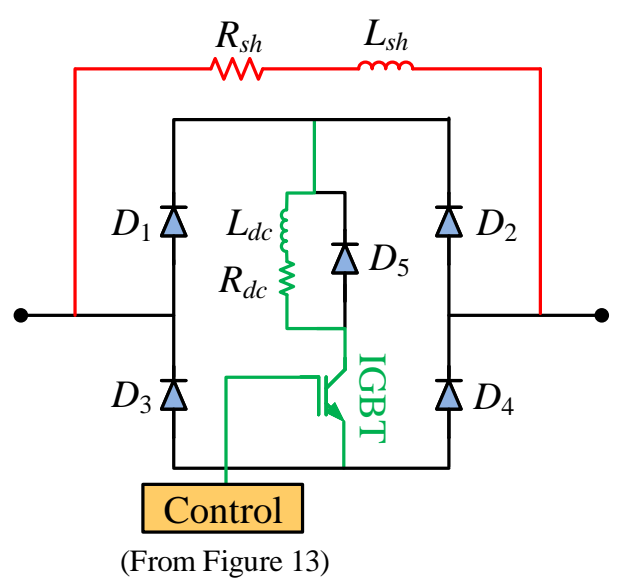

Figure 12. Architecture of the BFCL.

\subsubsection{Working Principle of the Bridge-Type Fault Current Limiter (BFCL)}

During normal condition, the current passes through the path $D_{1}-L_{d c}-R_{d c}-I G B T-D_{4}$ during positive half cycle and $D_{3}-I G B T-R_{d c}-L_{d c}-D_{2}$ path during negative half cycle. The shunt path has a high impedance value that makes the bridge switch carry all the line current except some leakage current of negligible magnitude $[12,27-29,36]$.

\subsubsection{Control Scheme for the BFCL}

The instantaneous voltage at the PCC is used as the input for the controller of the BFCL as represented in Figure 13. The $V_{d q, \phi}$ is constantly monitored and compared with the reference threshold value, $V_{t h}$. When the difference between the $V_{d q, \phi}$ and $V_{t h}$ is positive, a HIGH state signal is supplied to the gate of IGBT. So the IGBT is ON during normal condition and the shunt path is not in use. During fault, the $V_{d q, \phi}$ reduces and the difference between $V_{d q, \phi}$ and $V_{t h}$ becomes negative. When this happens, a LOW state signal is supplied to the gate of IGBT and it is turned OFF, which makes the bridge circuit open and the fault current gets diverted to the shunt path. The high resistance and inductance of the shunt path cease the fault current down to a considerable limit and the system stabilizes soon after $[12,29,36]$.

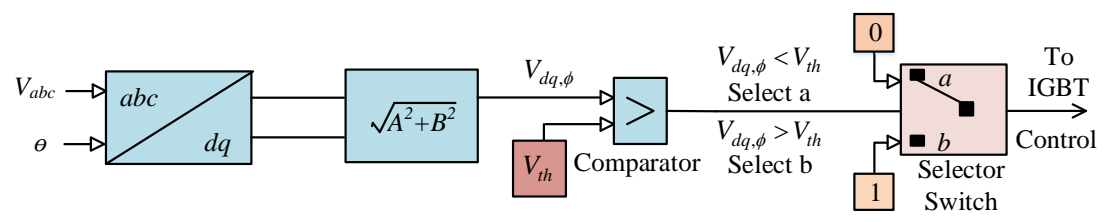

Figure 13. Control scheme of the Series Dynamic Braking Resistor (SDBR), the BFCL and the BFC-NSFCL.

\subsubsection{BFCL Design Consideration}

Different parameters of the BFCL are shown in Table 2. The values of $R_{s h}, L_{s h}, R_{d c}$ and $L_{d c}$ are selected based on the analysis carried out in Reference [27]. For making the comparison compatible, the value of shunt inductance is kept same as the inductance of primary coil $\left(L_{p}\right)$ of BFC-NSFCL.

Table 2. Parameters of the BFCL.

\begin{tabular}{cccc}
\hline $\boldsymbol{R}_{\boldsymbol{s h}}$ & $\boldsymbol{L}_{\boldsymbol{s h}}$ & $\boldsymbol{R}_{\boldsymbol{d c}}$ & $\boldsymbol{L}_{\boldsymbol{d c}}$ \\
\hline $20 \Omega$ & $250 \mathrm{mH}$ & $0.003 \Omega$ & $1 \mathrm{mH}$ \\
\hline
\end{tabular}




\subsection{SDBR Construction}

The basic construction of a SDBR has a resistor in parallel with an IGBT switch as depicted in Figure 14. In this study, an IGBT is used as a switch due to its special features such as quick response and compatible design. The SDBR is a well-known and proved technique and literature agrees that it has the potentiality to augment the FRT capability of wind power generation systems [33,34].

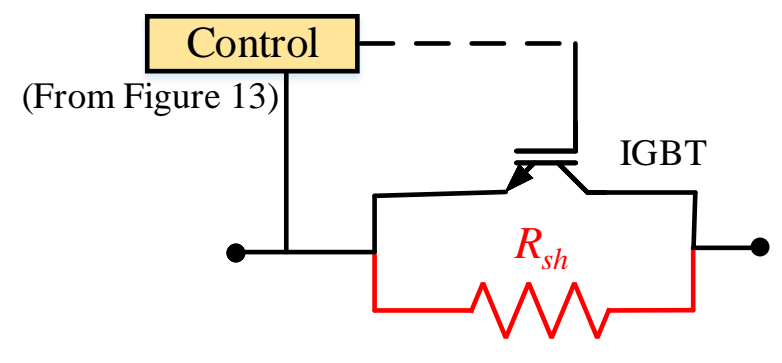

Figure 14. Architecture of the SDBR.

Working Principle of the SDBR

In the normal operating mode, the SDBR will operate with the closed IGBT switch. The gate pulse ofFigure IGBT is controlled according to Figure 13. During this period, the IGBT is in HIGH state and will bypass the braking resistor. When fault occurs, the line current rises sharply. The controller sends a zero or LOW signal to the gate of IGBT and the IGBT is opened. The line current thus flows through the only available shunt path $[33,34]$. To make a valid comparison, the braking resistor's value is kept $20 \Omega$ in comparison to BFCL.

\section{Simulation Results and Discussions}

To demonstrate the efficacy of the system model, both temporary and permanent faults are considered at the point $\mathrm{F}$ of the considered system model in Figure 4. Both scenarios are discussed in the following subsections. All the turbines in the system have same performance. However, turbine \#1 performance is only shown for the comparison.

\subsection{Temporary Fault Responses}

In this scenario, both symmetrical (triple line to ground-3LG as the most severe) and unsymmetrical (single line to ground-1LG as the most common) faults take place at time $t=0.1 \mathrm{~s}$. The fault is applied for $100 \mathrm{~ms}$ and the CBs of the faulty line are opened at $\mathrm{t}=0.2 \mathrm{~s}$ to clear the fault and reclosed at $t=1.2 \mathrm{~s}$. Since the applied fault is cleared at $t=0.2 \mathrm{~s}$ that means successful reclosure of CBs occurs at $t=1.2 \mathrm{~s}$. Both symmetrical and unsymmetrical faults responses are discussed in the following subsections.

\subsubsection{Symmetrical Fault Responses}

When the system faces a symmetrical fault, six different responses are depicted in Figure 15. The voltage response of the farm at the PCC is illustrated in Figure 15a. In case of no FCL, the output voltage goes to zero during fault. The BFC-NSFCL outperforms the BFCL and the SDBR in all aspect. However, the nonlinear controller based BFC-NSFCL provides the best performance. It displays the smallest sag and has the lowest fluctuations. It can be said that the nonlinear controller based BFC-NSFCL is the best choice for ameliorating the voltage response of the PCC compared to other considered devices. 


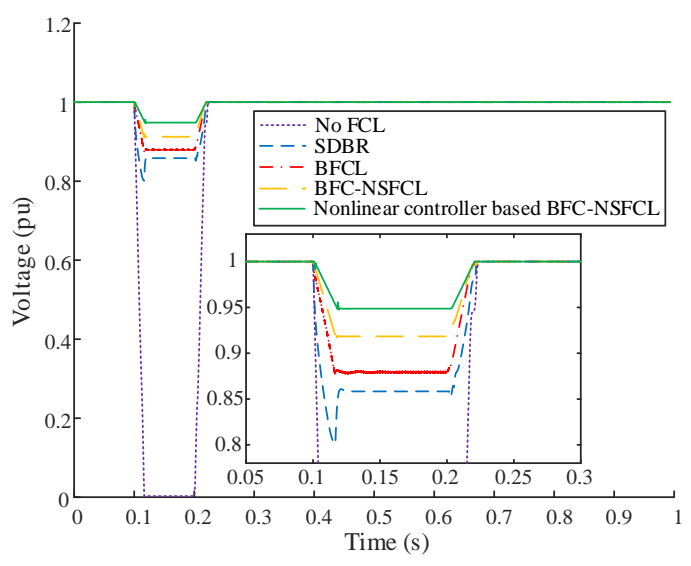

(a)

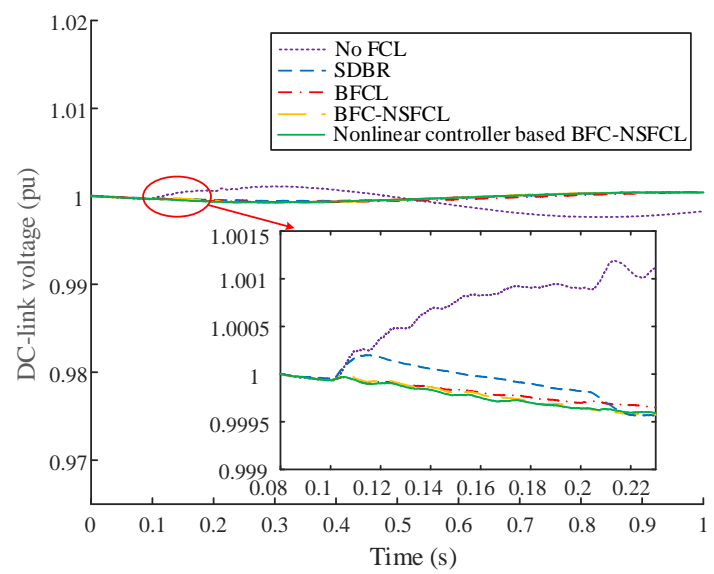

(c)

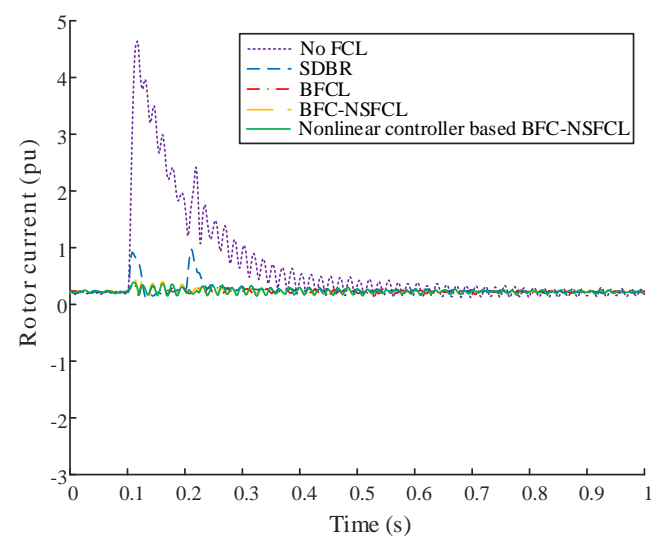

(e)

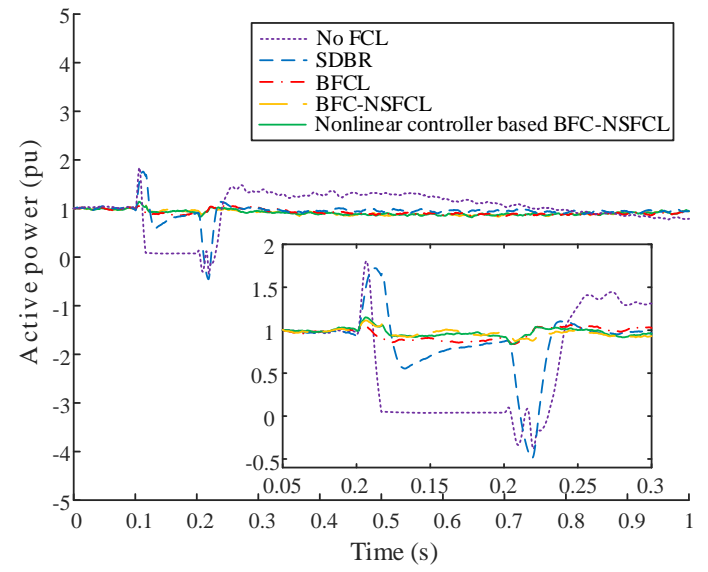

(b)

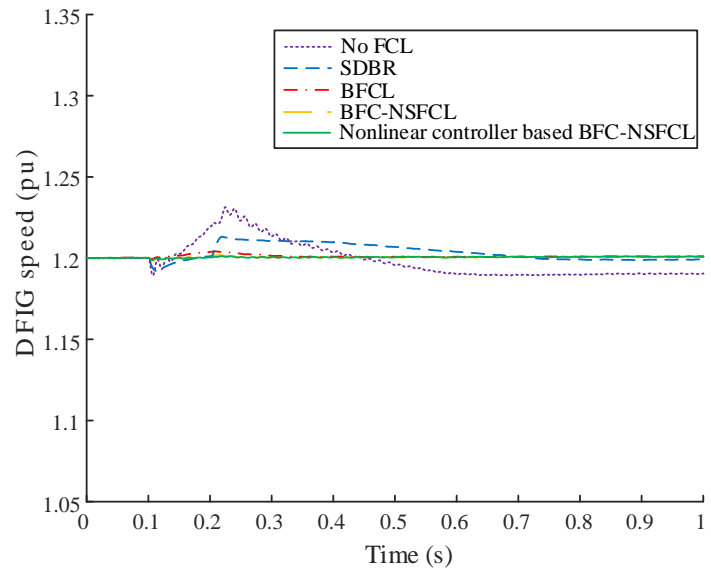

(d)

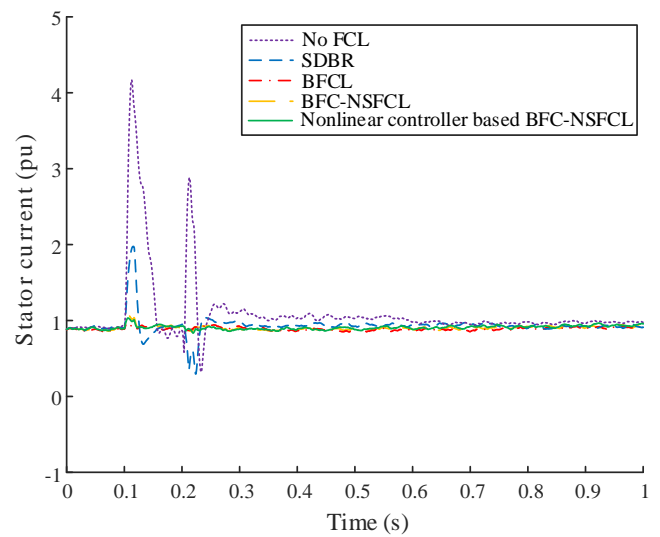

(f)

Figure 15. System responses for temporary 3LG fault: (a) Voltage at the PCC; (b) Active power at the Point of Common Coupling (PCC); (c) DC-link voltage; (d) DFIG speed; (e) Rotor current and (f) Stator current.

The active power response of the farm measured at the PCC is shown in Figure 15b. Without any FCL, the active power becomes very low. There is an abrupt rise of active power because of the mismatch between the extracted and the demanded wind power at the instant of opening of CBs. Though the SDBR and the BFCL can minimize certain power fluctuations but the BFC-NSFCL and the nonlinear controller based BFC-NSFCL show minimum amount of power fluctuations and sag. Figure 15c shows the DC-link voltage profile of the DFIG associated with the WT\#1. The traditional 
FCLs (SDBR and BFCL) can keep the DC-link voltage within the reference level but they have some fluctuations. But the proposed BFC-NSFCL and the nonlinear controller based BFC-NSFCL are capable of keeping the least voltage fluctuations. Among those two, nonlinear controller based BFC-NSFCL provides the better result.

The speed profile of the DFIG at WT\#1 is presented in Figure 15d. Without any FCL, there is a sudden rise of speed at the instant of fault and a certain time is required to regain the pre-fault speed level. The proposed BFC-NSFCL has the lower speed deviations compared to the SDBR and the BFCL. However, the nonlinear controller based BFC-NSFCL shows the best performance which is quite noticeable. The rotor and stator currents of the DFIG associated with the WT\#1 are depicted in Figure 15e,f respectively. In order to protect the converters and maintain a stable operation of the DFIG, the abrupt rise of stator and rotor current during fault needs to be suppressed. In the case of no FCL, rotor current and stator current become few times higher than the pre-fault level and returns to the pre-fault level after a certain time. It is clear that the proposed BFC-NSFCL has lower current rise in comparison with the SDBR and the BFCL but the nonlinear controller based BFC-NSFCL has the lowest current rise and minimum fluctuations.

\subsubsection{Unsymmetrical Fault Responses}

When the system experiences an unsymmetrical fault, the responses of the considered scenarios are depicted in Figure 16. The voltage profile of the farm at the PCC is represented in Figure 16a. Without any FCL, the voltage goes to around $60 \%$ of the pre-fault level and recovers after the opening of the breakers. The BFC-NSFCL outperforms both the BFCL and the SDBR in all aspects but the zoomed view clearly indicates that the nonlinear controller based BFC-NSFCL has the lowest perturbation and minimum amount of sag. Figure $16 \mathrm{~b}$ represents the active power profile of the PCC for 1LG fault. There is certain amount of deviations for all the methods but it is also noticeable that the nonlinear controller based BFC-NSFCL will be the best candidate for retaining the stable output power of wind farm. The DC-link voltage of the DFIG at WT\#1 has no abrupt jump to a substantial value for 1LG fault as shown in Figure 16c. However, the BFC-NSFCL and the nonlinear controller based BFC-NSFCL can hold the DC-link voltage fluctuation to the minimum level compared to the other methods.

The speed profile of the DFIG at WT\#1 is represented in Figure 16d for 1LG fault. In case of no FCL, there are a certain amount of fluctuations in rotor speed. As a result, the turbine generator's electromechanical system confronts the maximum stress. The BFC-NSFCL has less fluctuations than that of the BFCL and the SDBR, but the nonlinear controller based BFC-NSFCL has the best response. It is evident from the Figure 16e, f that, the rotor and stator currents are subdued to the minimum level by the BFC-NSFCL. Without any FCL, current becomes insignificantly high. Conventionally used FCLs (SDBR and BFCL) are also capable of current suppression but significantly inferior to the proposed BFC-NSFCL. The steady state operation of the DFIGs are guaranteed by the nonlinear controller based BFC-NSFCL because it offers least stresses to the converters. 


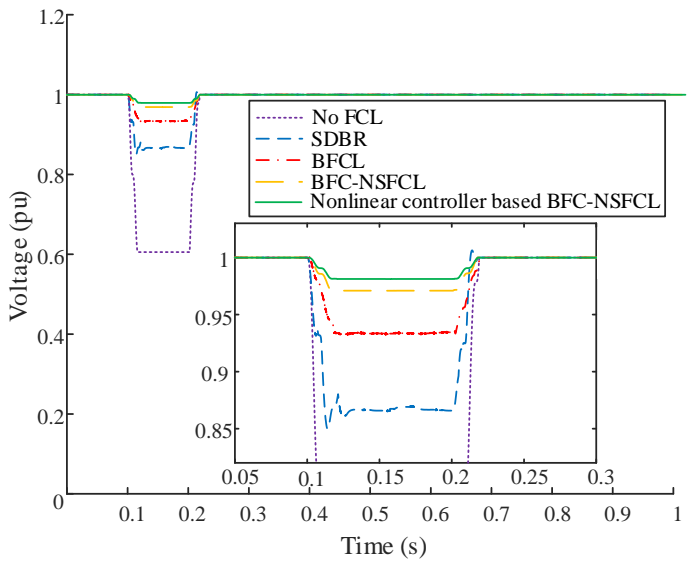

(a)

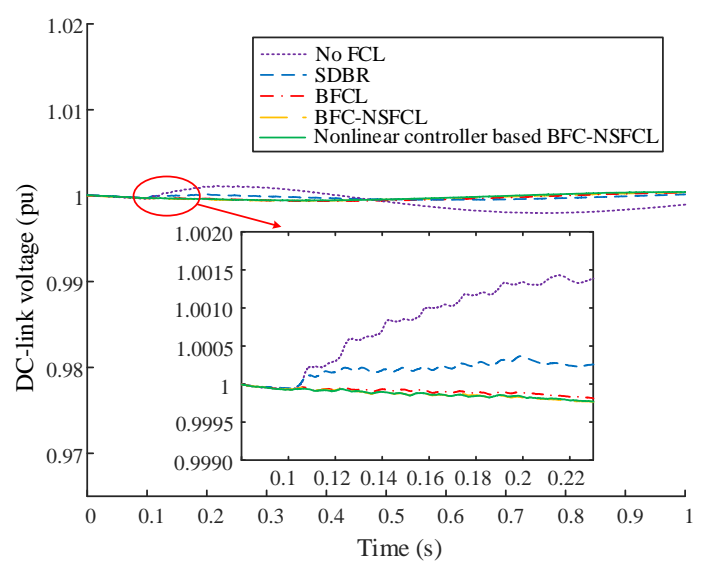

(c)

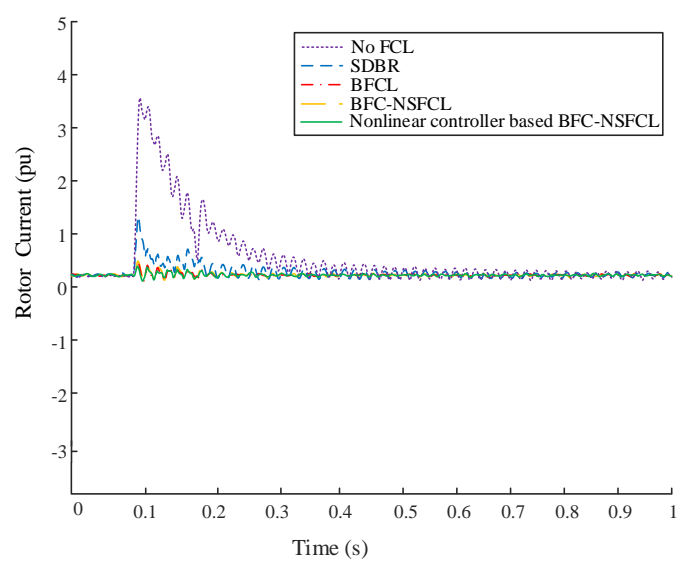

(e)

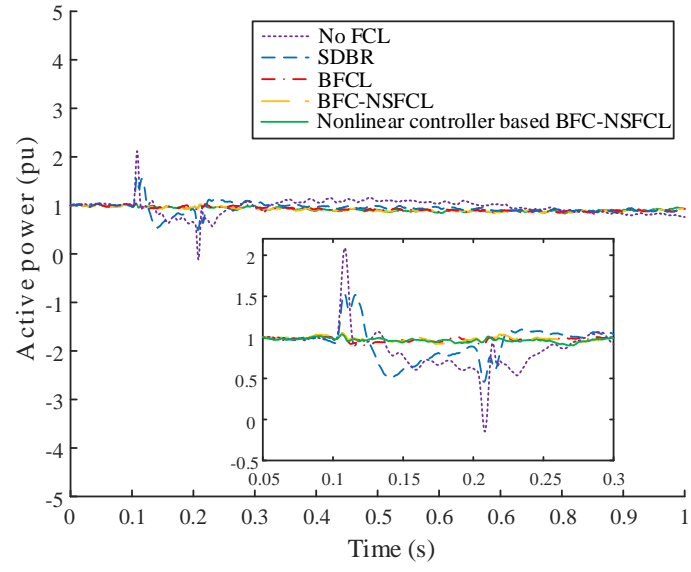

(b)

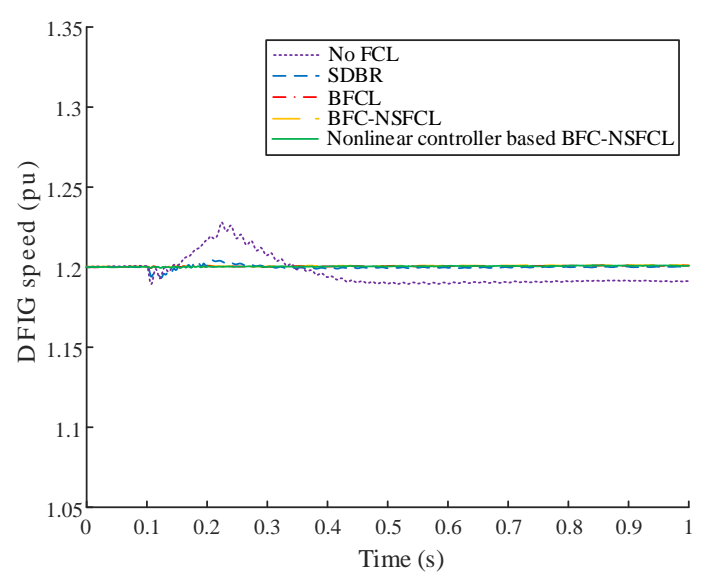

(d)

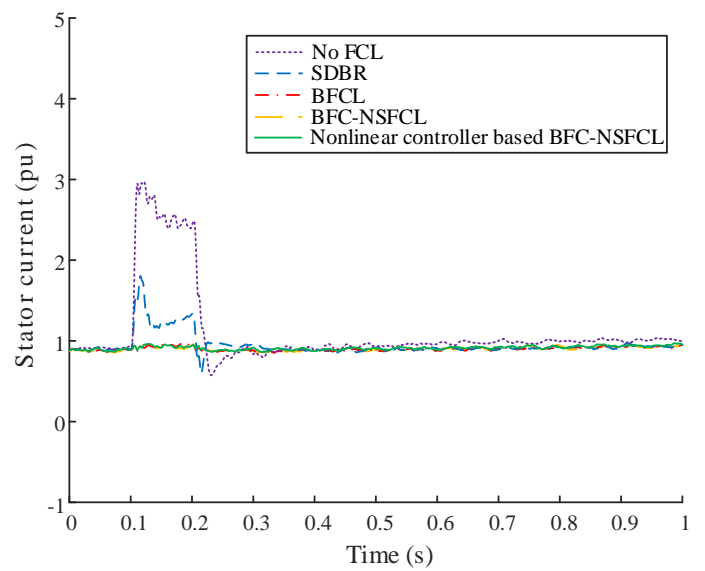

(f)

Figure 16. System responses for temporary 1LG fault: (a) Voltage at the PCC; (b) Active power at the PCC; (c) DC-link voltage; (d) DFIG speed; (e) Rotor current and (f) Stator current.

\subsubsection{Index-Based Analysis for Temporary Fault}

For the numerical verification, an index based comparison is carried out to find out the performance of each FCLs $[12,27,36]$. The indices are titled as $v l t(p u . s)$, pow(pu.s), dclink(pu.s), 
$s p d(p u . s), r t r(p u . s)$ and $\operatorname{str}(p u . s)$. The indices are calculated with certain mathematical expressions which are stated from (33) to (38).

$$
\begin{aligned}
\operatorname{vlt}(\text { pu.s }) & =\int_{0}^{T}|\Delta V| d t \\
\operatorname{pow}(\text { pu.s }) & =\int_{0}^{T}|\Delta P| d t \\
\operatorname{dclink}(\text { pu.s }) & =\int_{0}^{T}\left|\Delta V_{d c}\right| d t \\
\operatorname{spd}(\text { pu.s }) & =\int_{0}^{T}|\Delta \omega| d t \\
\operatorname{rtr}(\text { pu.s }) & =\int_{0}^{T}\left|\Delta I_{r}\right| d t \\
\operatorname{str}(\text { pu.s }) & =\int_{0}^{T}\left|\Delta I_{s}\right| d t
\end{aligned}
$$

here $\Delta V, \Delta P, \Delta V_{d c}, \Delta \omega, \Delta I_{r}$ and $\Delta I_{s}$ are the deviations of PCC voltage, active power, DC-link voltage, generator speed, rotor current and stator current respectively. The indices are measured within a time interval of $T$. In this work, the value of $T$ is kept from 0 to $1 \mathrm{~s}$ for temporary fault. Since the equations consist of deviations, the lesser the value of the indices the better wind generator's fault ride through performance. The performance indices for symmetrical (3LG) and unsymmetrical (1LG) faults are shown in the Tables 3 and 4 respectively.

Table 3. Performance indices for temporary symmetrical (3LG) fault.

\begin{tabular}{cccccc}
\hline & \multicolumn{5}{c}{ Values of Indices } \\
\cline { 2 - 6 } Index Parameters (\%) & No FCL & SDBR & BFCL & BFC-NSFCL & $\begin{array}{c}\text { Nonlinear } \\
\text { Controller Based } \\
\text { BFC-NSFCL }\end{array}$ \\
\hline vlt(pu.s) & 10.145 & 1.614 & 1.241 & 0.993 & 0.681 \\
pow(pu.s) & 27.327 & 12.281 & 7.151 & 6.165 & 6.112 \\
dclink(pu.s) & 0.112 & 0.037 & 0.034 & 0.032 & 0.028 \\
spd(pu.s) & 0.869 & 0.442 & 0.101 & 0.073 & 0.050 \\
rtr(pu.s) & 46.838 & 4.739 & 2.135 & 2.092 & 2.065 \\
str(pu.s) & 21.706 & 18.148 & 2.655 & 2.604 & 2.386 \\
\hline
\end{tabular}

Table 4. Performance indices for temporary unsymmetrical (1LG) fault.

\begin{tabular}{cccccc}
\hline & \multicolumn{5}{c}{ Values of Indices } \\
\cline { 2 - 6 } Index Parameters (\%) & No FCL & SDBR & BFCL & BFC-NSFCL & $\begin{array}{c}\text { Nonlinear } \\
\text { Controller Based } \\
\text { BFC-NSFCL }\end{array}$ \\
\hline vlt(pu.s) & 3.982 & 1.314 & 0.670 & 0.319 & 0.212 \\
pow(pu.s) & 11.808 & 8.483 & 3.057 & 2.566 & 2.106 \\
dclink(pu.s) & 0.101 & 0.036 & 0.031 & 0.028 & 0.027 \\
spd(pu.s) & 0.291 & 0.086 & 0.058 & 0.047 & 0.034 \\
rtr(pu.s) & 34.220 & 3.245 & 1.754 & 1.685 & 1.583 \\
str(pu.s) & 18.462 & 6.977 & 2.006 & 1.862 & 1.751 \\
\hline
\end{tabular}

As it can be seen from the Tables 3 and 4, the performance indices are maximum for no FCL and in the case of the BFC-NSFCL, the values of indices are smaller than the SDBR and the BFCL. But for nonlinear controller based BFC-NSFCL, the values of indices are the least. This is true for both symmetrical and unsymmetrical faults. Since the performance of the FCLs are inversely related to 
their corresponding percentage indices, it can be said that the nonlinear controller based BFC-NSFCL performs the best to improve system stability.

\subsubsection{Steady State Analysis of Temporary Faults}

To understand the superiority of our proposed BFC-NSFCL and nonlinear controller based BFC-NSFCL, a steady state analysis of the responses for different FCLs during temporary faults were carried out. The findings of this analysis are presented in Tables 5 and 6 respectively. The tables represent the percentage overshoot and settling time of the active power at the PCC, DC-link voltage, DFIG speed, rotor current and stator current responses. The analysis for voltage responses of the PCC are not shown in the tables as they do not exhibit any overshoot for any of the FCLs we used in this work.

Table 5 represents the steady state analysis for temporary symmetrical (3LG) fault. As it can be seen, the percentage overshoot and the settling time without any FCL is the highest in all five responses. After implementing FCLs, the percentage overshoot and the settling time reduced significantly. Compared to the SDBR and the BFCL, the BFC-NSFCL has smaller percentage overshoot and lower settling time. However, the percentage overshoot and the settling time are the least for nonlinear controller based BFC-NSFCL. Similarly, for temporary unsymmetrical fault, the BFC-NSFCL and the nonlinear controller based BFC-NSFCL shows the best results as we can observe from the data provided in Table 6.

Table 5. Steady state analysis for temporary symmetrical (3LG) fault.

\begin{tabular}{|c|c|c|c|c|c|c|c|c|c|c|}
\hline \multirow[b]{2}{*}{ FCLs } & \multicolumn{5}{|c|}{ Percentage Overshoot } & \multicolumn{5}{|c|}{ Settling Time (s) } \\
\hline & $\begin{array}{l}\text { Active } \\
\text { Power }\end{array}$ & $\begin{array}{l}\text { DC-Link } \\
\text { Voltage }\end{array}$ & $\begin{array}{l}\text { DFIG } \\
\text { Speed }\end{array}$ & $\begin{array}{l}\text { Rotor } \\
\text { Current }\end{array}$ & $\begin{array}{l}\text { Stator } \\
\text { Current }\end{array}$ & $\begin{array}{l}\text { Active } \\
\text { Power }\end{array}$ & $\begin{array}{l}\text { DC-Link } \\
\text { Voltage }\end{array}$ & $\begin{array}{l}\text { DFIG } \\
\text { Speed }\end{array}$ & $\begin{array}{l}\text { Rotor } \\
\text { Current }\end{array}$ & $\begin{array}{l}\text { Stator } \\
\text { Current }\end{array}$ \\
\hline No FCL & 44.884 & 0.133 & 2.158 & 95.150 & 79.424 & 12.838 & $\infty$ & 16.915 & 4.754 & 1.744 \\
\hline SDBR & 43.531 & 0.051 & 0.967 & 76.859 & 55.683 & 0.645 & 2.562 & 5.334 & 0.581 & 0.935 \\
\hline BFCL & 8.263 & 0.048 & 0.210 & 36.387 & 6.798 & 0.178 & 1.079 & 0.134 & 0.572 & 0.585 \\
\hline BFC-NSFCL & 6.063 & 0.043 & 0.065 & 27.279 & 2.411 & 0.111 & 0.613 & 0.051 & 0.531 & 0.542 \\
\hline $\begin{array}{l}\text { Nonlinear controller } \\
\text { based BFC-NSFCL }\end{array}$ & 5.483 & 0.040 & 0.010 & 25.619 & 1.961 & 0.105 & 0.534 & 0.046 & 0.339 & 0.253 \\
\hline
\end{tabular}

Table 6. Steady state analysis for temporary unsymmetrical (1LG) fault.

\begin{tabular}{cccccccccccc}
\hline & \multicolumn{4}{c}{ Percentage Overshoot } & \multicolumn{4}{c}{ Settling Time (s) } \\
\cline { 2 - 11 } FCLs & $\begin{array}{c}\text { Active } \\
\text { Power }\end{array}$ & $\begin{array}{l}\text { DC-Link } \\
\text { Voltage }\end{array}$ & $\begin{array}{l}\text { DFIG } \\
\text { Speed }\end{array}$ & $\begin{array}{c}\text { Rotor } \\
\text { Current }\end{array}$ & $\begin{array}{c}\text { Stator } \\
\text { Current }\end{array}$ & $\begin{array}{c}\text { Active } \\
\text { Power }\end{array}$ & $\begin{array}{c}\text { DC-Link } \\
\text { Voltage }\end{array}$ & $\begin{array}{c}\text { DFIG } \\
\text { Speed }\end{array}$ & $\begin{array}{c}\text { Rotor } \\
\text { Current }\end{array}$ & $\begin{array}{c}\text { Stator } \\
\text { Current }\end{array}$ \\
\hline No FCL & 53.405 & 0.132 & 2.049 & 93.685 & 71.016 & 11.252 & 12.984 & 15.192 & 2.975 & 0.974 \\
SDBR & 34.248 & 0.049 & 0.474 & 83.028 & 51.382 & 0.506 & 4.168 & 0.269 & 0.395 & 0.751 \\
BFCL & 10.029 & 0.048 & 0.032 & 49.288 & 9.374 & 0.456 & 0.934 & 0.066 & 0.273 & 0.418 \\
$\begin{array}{c}\text { BFC-NSFCL } \\
\text { Nonlinear controller }\end{array}$ & 9.492 & 0.045 & 0.030 & 45.237 & 8.818 & 0.073 & 0.554 & 0.045 & 0.210 & 0.386 \\
based BFC-NSFCL & 5.443 & 0.044 & 0.029 & 36.504 & 8.462 & 0.051 & 0.498 & 0.033 & 0.183 & 0.242 \\
\hline
\end{tabular}

\subsection{Permanent Fault Responses}

This scenario represents a 3LG and 1LG permanent fault occurring at point F in Figure 4. The fault starts at $t=0.1 \mathrm{~s}$ and continues for indefinite time. The CBs on the faulty lines are opened at $t=0.2 \mathrm{~s}$ and reclosed again at $t=1.2 \mathrm{~s}$. Unfortunately, the fault still exists at $t=1.2 \mathrm{~s}$ and therefore, an unsuccessful reclosure of CBs takes place. Therefore, the $\mathrm{CBs}$ are opened once again at $t=1.3 \mathrm{~s}$ and remained open because of permanent fault.

The voltage responses of the farm at the PCC for 3LG and 1LG permanent fault are displayed in Figure 17. It is clearly noticeable that the BFC-NSFCL performs better than that of the SDBR and the BFCL but the nonlinear controller based BFC-NSFCL is the best candidate during permanent faults to augment the FRT capability of DFIG. 


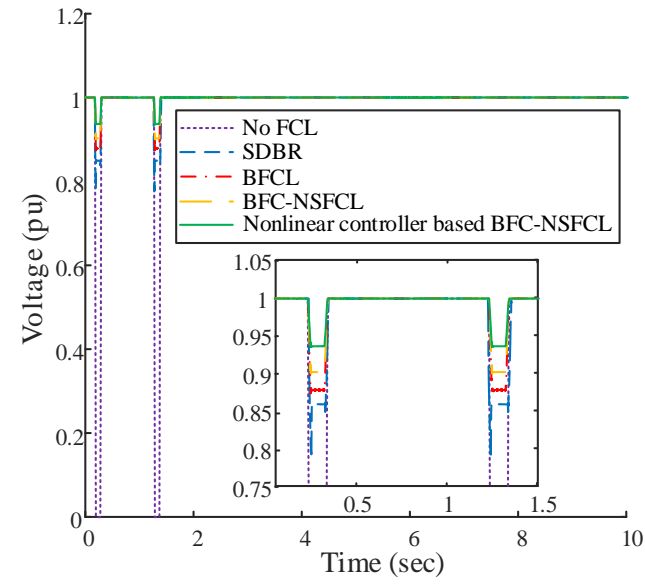

(a)

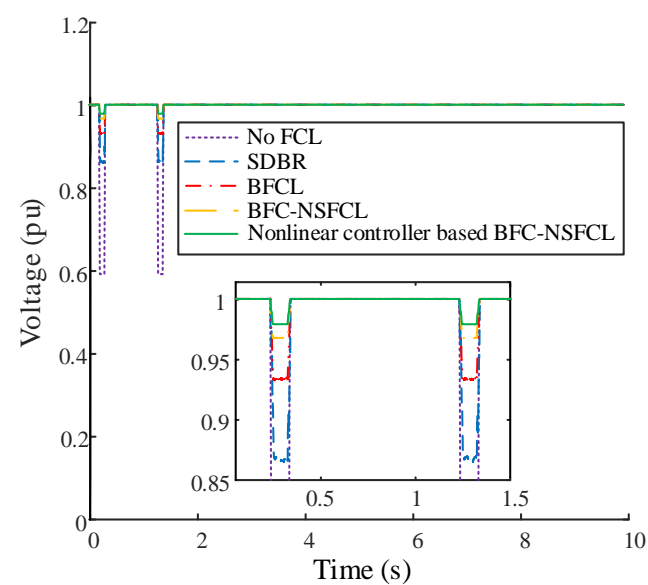

(b)

Figure 17. Voltage responses at the PCC for (a) 3LG permanent fault and (b) 1LG permanent fault.

\subsubsection{Index Based Analysis for Permanent Fault}

Performance indices for symmetrical and unsymmetrical faults are shown in Tables 7 and 8 respectively. Similar to temporary fault analysis, the indices of permanent fault also demonstrate the efficacy of the proposed BFC-NSFCL and the nonlinear controller based BFC-NSFCL.

Table 7. Performance indices for permanent symmetrical (3LG) fault.

\begin{tabular}{cccccc}
\hline & \multicolumn{5}{c}{ Values of Indices } \\
\cline { 2 - 6 } Index Parameters (\%) & No FCL & SDBR & BFCL & BFC-NSFCL & $\begin{array}{c}\text { Nonlinear Controller } \\
\text { Based BFC-NSFCL }\end{array}$ \\
\hline vlt(pu.s) & 20.266 & 3.226 & 2.491 & 1.993 & 1.294 \\
pow(pu.s) & 65.942 & 32.846 & 22.871 & 19.397 & 16.745 \\
dclink(pu.s) & 0.882 & 0.175 & 0.146 & 0.111 & 0.099 \\
spd(pu.s) & 14.675 & 4.437 & 3.148 & 3.088 & 2.966 \\
rtr(pu.s) & 108.096 & 23.375 & 15.094 & 14.666 & 13.921 \\
str(pu.s) & 55.758 & 42.689 & 23.925 & 21.476 & 18.112 \\
\hline
\end{tabular}

Table 8. Performance indices for permanent unsymmetrical (1LG) fault.

\begin{tabular}{cccccc}
\hline \multirow{2}{*}{ Index Parameters (\%) } & \multicolumn{5}{c}{ Values of Indices } \\
\cline { 2 - 6 } & No FCL & SDBR & BFCL & BFC-NSFCL & $\begin{array}{c}\text { Nonlinear Controller } \\
\text { Based BFC-NSFCL }\end{array}$ \\
\hline vlt(pu.s) & 7.955 & 2.534 & 1.296 & 0.633 & 0.459 \\
pow(pu.s) & 25.895 & 18.848 & 7.985 & 5.459 & 5.284 \\
dclink(pu.s) & 0.207 & 0.104 & 0.059 & 0.056 & 0.053 \\
spd(pu.s) & 10.848 & 3.489 & 1.486 & 1.349 & 1.255 \\
rtr(pu.s) & 75.949 & 15.895 & 7.386 & 6.386 & 5.898 \\
str(pu.s) & 38.848 & 20.846 & 8.488 & 7.885 & 7.579 \\
\hline
\end{tabular}

\subsubsection{Steady State Analysis of Permanent Faults}

Steady state analysis for permanent symmetrical and unsymmetrical faults are shown in Tables 9 and 10 respectively. Likewise, the BFC-NSFCL and the nonlinear controller based BFC-NSFCL shows the best performance in terms of having lowest overshoot and settling time. For the analysis, two different scenarios were considered that is, when CBs open for the first time and when the CBs open again due to unsuccessful re-closure as the fault still persists. Observing the percentage overshoot for all FCLs, it is evident that the BFC-NSFCL and the nonlinear controller based BFC-NSFCL have the least overshoot for all responses similar to that we have seen during temporary 
faults. For some responses, calculating the settling time after the first sag is not applicable because the CBs open again due to permanent fault before the responses can reach the steady state. These responses are denoted by "N/A" in the Tables 9 and 10. The settling time after the CBs open for the second time was calculated also for all the responses and the BFC-NSFCL and the nonlinear controller based BFC-NSFCL has the least settling time than the SDBR and the BFCL.

Table 9. Steady state analysis for permanent symmetrical (3LG) fault.

\begin{tabular}{|c|c|c|c|c|c|c|c|c|c|c|c|c|c|c|c|c|c|c|c|c|}
\hline \multirow{3}{*}{ FCLs } & \multicolumn{10}{|c|}{ Overshoot } & \multicolumn{10}{|c|}{ Settling Time } \\
\hline & \multicolumn{2}{|c|}{ Active Power } & \multicolumn{2}{|c|}{ DC-Link Voltage } & \multicolumn{2}{|c|}{ DFIG Speed } & \multicolumn{2}{|c|}{ Rotor Current } & \multicolumn{2}{|c|}{ Stator Current } & \multicolumn{2}{|c|}{ Active Power } & \multicolumn{2}{|c|}{ DC-Link Voltage } & \multicolumn{2}{|c|}{ DFIG Speed } & \multicolumn{2}{|c|}{ Rotor Current } & \multicolumn{2}{|c|}{ Stator Current } \\
\hline & 1st sag & 2nd sag & 1st sag & 2nd sag & 1st sag & 2nd sag & 1st sag & 2nd sag & 1st sag & 2nd sag & 1st sag & 2nd sag & 1st sag & 2nd sag & 1st sag & 2nd sag & 1st sag & 2nd sag & 1st sag & 2nd sag \\
\hline No & 49. & 46.460 & 0.099 & 0.299 & 2.201 & 1.534 & 94.592 & $\begin{array}{ll}94.607 \\
\end{array}$ & 79.059 & 77.400 & $\mathrm{~N} / \mathrm{A}$ & 14.146 & $\mathrm{~N} / \mathrm{A}$ & $\infty$ & $\mathrm{N} / \mathrm{A}$ & 21.264 & $\mathrm{~N} / \mathrm{A}$ & 4.980 & $\mathrm{~N} / \mathrm{A}$ & 1.989 \\
\hline & & & & & & 1. & & & & & & & & & & & & & & 88 \\
\hline $\mathrm{BF}$ & $\begin{array}{l}17.279 \\
1.6123\end{array}$ & 17.883 & 0.041 & 0.038 & 1.194 & 1.291 & 33.030 & 36.012 & 9.285 & 13.354 & 0.205 & 0.319 & N/A & 1.098 & 1.057 & 0.238 & 0.597 & 0.741 & 0.718 & 0.774 \\
\hline $\begin{array}{l}\text { ne-NSF } \\
\text { nlinear con }\end{array}$ & 16.123 & & & & & & & & & & & & & & & & & & & \\
\hline based BFC-NSFCL & 15.174 & 15.572 & 0.015 & 0.017 & 0.249 & 0.332 & 23.219 & 26.275 & 3.519 & 5.869 & 0.105 & 0.151 & 0.619 & 0.668 & 0.032 & 0.036 & 0.314 & 0.321 & 0.242 & 0.250 \\
\hline
\end{tabular}

Table 10. Steady state analysis for permanent unsymmetrical (1LG) fault.

\begin{tabular}{|c|c|c|c|c|c|c|c|c|c|c|c|c|c|c|c|c|c|c|c|c|}
\hline \multirow{2}{*}{ FCLs } & \multicolumn{10}{|c|}{ Overshoot } & \multicolumn{10}{|c|}{ Settling Time } \\
\hline & \multicolumn{2}{|c|}{ Active Power } & \multicolumn{2}{|c|}{ DC-Link Voltage } & \multicolumn{2}{|c|}{ DFIG Speed } & \multicolumn{2}{|c|}{ Rotor Current } & \multicolumn{2}{|c|}{ Stator Current } & \multicolumn{2}{|c|}{ Active Power } & \multicolumn{2}{|c|}{ DC-Link Voltage } & \multicolumn{2}{|c|}{ DFIG Speed } & \multicolumn{2}{|c|}{ Rotor Current } & \multicolumn{2}{|c|}{ Stator Current } \\
\hline & & & & & & & & & & 69 & & & $\mathrm{~N}$ & & & & & & & 1.906 \\
\hline & & & & & & & & & & & & & & & & & & & & 1.291 \\
\hline $3 F C-1$ & 16.9 & 17 & 0.0 & 0.8 & 0. & 0. & 39. & 41. & 2 & 3. & 0. & 0.101 & 0. & & 0.071 & 0.18 & 0.3 & $0 .{ }^{2}$ & 0.462 & 0.532 \\
\hline $\begin{array}{l}\text { Nonlinear contronler } \\
\text { based BFC-NSFCL }\end{array}$ & 16.512 & 16.821 & 0.010 & 0.010 & 0.125 & 0.200 & 38.575 & 40.191 & 1.392 & 2.746 & 0.054 & 0.058 & 0.518 & 0.884 & 0.065 & 0.114 & 0.297 & 0.509 & 0.339 & 0.421 \\
\hline
\end{tabular}

$\mathrm{N} / \mathrm{A}=$ Not applicable as the CBs open again before the responses can reach steady state.

\section{Practical Feasibility and Cost Analysis}

The Flux Coupling Superconducting Fault Current Limiter (FC-SFCL) [42] works fine to augment the FRT capability of DFIG based wind farms. However, the reactor of the FC-SFCL has superconducting coil that is indeed a costly material and very hard to commercialize. Whereas, the reactor of the BFC-NSFCL utilizes copper which is cheaper and more available alternative to the superconductor. For example, if we assume the reactors as air core type, the cheapest high temperature superconductor has 2 to 10 times the material cost than the copper [43]. That makes the FC-SFCL less efficient and less practical for small and medium scale wind farms.

Moreover, the construction of FC-SFCL requires two reverse-blocking antiparallel IGBTs (RB-IGBTs) connected at the secondary coil with two gate drivers one each for a RB-IGBT. But for the BFC-NSFCL, a single bridge switch with a single gate driver can replace the two RB-IGBTs of the FC-SFCL. Since the cost of a bridge switch is almost identical to the cost of a RB-IGBT, the cost of the BFC-NSFCL is significantly reduced. This increases the practical feasibility of our proposed BFC-NSFCL with a reduced cost.

\section{Conclusions}

This paper has proposed a BFC-NSFCL to improve the FRT capability of the grid connected wind farm. Further, for controlling the operation of the BFC-NSFCL, a nonlinear controller is introduced to optimally design the dynamic control variable in the control loop. The controller's design approach responds according to the severity level of the fault in the system. Additionally, the performance of this proposed FCL is compared with the performance of two other frequently used conventional FCLs (BFCL and SDBR). Observing the simulation results and several numerical analyses, the following summaries can be reached:

- Without any FCL, the system experiences substantial consequences during fault.

- The BFC-NSFCL performs superior to that of the BFCL and SDBR under different fault conditions such as subjecting the system to successful and unsuccessful reclosing of the CBs during symmetrical and unsymmetrical grid fault conditions.

- Finally, the nonlinear controller based BFC-NSFCL provides smoother and faster response compared to the BFC-NSFCL without any controller. It also provides swift convergence during steady situation as evident from the better overshoot and settling time parameters. 
In this study, the proposed nonlinear controller based BFC-NSFCL provides good example of solving dynamic optimization problems of the wind farm's FRT capability. The challenges on the application of the proposed controller as well as the FCL lies on testing its authenticity practically. Moreover, a data driven optimization algorithm for the nonlinear controller is another challenge which is our future research direction.

Author Contributions: Conceptualization, M.R.I., M.N.H. and J.H.; methodology, M.R.I.; software, M.R.I., M.N.H. and J.H.; validation, M.A.H.S., A.A., T.K.R. and M.A.M.; formal analysis, M.R.I., M.N.H. and J.H.; writing-original draft preparation, M.N.H. and J.H.; writing-review and editing, M.R.I., M.A.H.S., A.A., T.K.R. and M.A.M.; supervision, M.A.H.S. and A.A. All authors have read and agreed to the published version of the manuscript.

Funding: This research received no external funding.

Conflicts of Interest: The authors declare no conflict of interest.

\section{Abbreviations}

The following abbreviations are used in this manuscript:

$\begin{array}{ll}\text { BFC-NSFCL } & \text { Bridge-Type Flux Coupling Non-Superconducting Fault Current Limiter } \\ \text { BFCL } & \text { Bridge-Type Fault Current Limiter } \\ \text { FC-SFCL } & \text { Flux Coupling Superconducting Fault Current Limiter } \\ \text { FCR } & \text { Flux Coupling Reactor } \\ \text { FRT } & \text { Fault Ride Through } \\ \text { GSC } & \text { Grid Side Converter } \\ \text { IGBT } & \text { Insulated Gate Bipolar Transistor } \\ \text { MFCL } & \text { Magnetic Fault Current Limiter } \\ \text { MOV } & \text { Metal Oxide Varistor } \\ \text { NSFCL } & \text { Non-Superconducting Fault Current Limiter } \\ \text { PCC } & \text { Point of Common Coupling } \\ \text { RSC } & \text { Rotor Side Converter } \\ \text { SDBR } & \text { Series Dynamic Braking Resistor } \\ \text { SFCL } & \text { Superconducting Fault Current Limiter } \\ \text { SMES } & \text { Superconducting Magnetic Energy Storage }\end{array}$

\section{Appendix A}

The parameters of the DFIG and the drive train are provided in the Table A1.

Table A1. Each DFIG and drive train data.

\begin{tabular}{cc}
\hline Parameter & Value \\
\hline Rated power & $1.5 \mathrm{MVA}$ \\
Rated voltage & $0.69 \mathrm{KV}$ \\
DC-link nominal voltage & $1.2 \mathrm{KV}$ \\
DC-link capacitance value & $12,000 \mu \mathrm{F}$ \\
Wind speed & $14 \mathrm{~ms}^{-1}$ \\
Frequency & $50 \mathrm{~Hz}$ \\
Resistance of stator & $0.005 \mathrm{pu}$ \\
Magnetizing inductance & $3.95279 \mathrm{pu}$ \\
Leakage inductance of stator & $0.09321 \mathrm{pu}$ \\
Inertia & 0.80 \\
Leakage inductance of wound rotor & $0.09955 \mathrm{pu}$ \\
Wound rotor resistance & $0.0055 \mathrm{pu}$ \\
Friction factor & 0.01 \\
\hline
\end{tabular}




\section{References}

1. Justo, J.J.; Mwasilu, F.; Jung, J.W. Doubly-fed induction generator based wind turbines: A comprehensive review of fault ride-through strategies. Renew. Sustain. Energy Rev. 2015, 45, 447-467. [CrossRef]

2. Hu, J.; Wang, B.; Wang, W.; Tang, H.; Chi, Y.; Hu, Q. Small signal dynamics of DFIG-based wind turbines during riding through symmetrical faults in weak AC grid. IEEE Trans. Energy Convers. 2017, 32, 720-730. [CrossRef]

3. Tohidi, S.; Behnam, M.I. A comprehensive review of low voltage ride through of doubly fed induction wind generators. Renew. Sustain. Energy Rev. 2016, 57, 412-419. [CrossRef]

4. Gounder, Y.K.; Nanjundappan, D.; Boominathan, V. Enhancement of transient stability of distribution system with SCIG and DFIG based wind farms using STATCOM. IET Renew. Power Gener. 2016, 10, 1171-1180. [CrossRef]

5. Wessels, C.; Gebhardt, F.; Fuchs, F.W. Fault ride-through of a DFIG wind turbine using a dynamic voltage restorer during symmetrical and asymmetrical grid faults. IEEE Trans. Power Electron. 2010, 26, 807-815. [CrossRef]

6. Pannell, G.; Zahawi, B.; Atkinson, D.J.; Missailidis, P. Evaluation of the performance of a DC-link brake chopper as a DFIG low-voltage fault-ride-through device. IEEE Trans. Energy Convers. 2013, 28, 535-542. [CrossRef]

7. Morren, J.; De Haan, S.W. Ridethrough of wind turbines with doubly-fed induction generator during a voltage dip. IEEE Trans. Energy Convers. 2005, 20, 435-441. [CrossRef]

8. Okedu, K.; Muyeen, S.; Takahashi, R.; Tamura, J. Comparative study between two protection schemes for DFIG-based wind generator. In Proceedings of the 2010 International Conference on Electrical Machines and Systems, Incheon, Korea, 10-13 October 2010; pp. 62-67.

9. Salles, M.; Cardoso, J.; Grilo, A.; Rahmann, C.; Hameyer, K. Control strategies of doubly fed induction generators to support grid voltage. In Proceedings of the 2009 IEEE International Electric Machines and Drives Conference, Miami, FL, USA, 3-6 May 2009; pp. 1551-1556.

10. Yang, J.; Fletcher, J.E.; O'Reilly, J. A series-dynamic-resistor-based converter protection scheme for doubly-fed induction generator during various fault conditions. IEEE Trans. Energy Convers. 2010, 25, 422-432. [CrossRef]

11. Qiao, W.; Venayagamoorthy, G.K.; Harley, R.G. Real-time implementation of a STATCOM on a wind farm equipped with doubly fed induction generators. IEEE Trans. Ind. Appl. 2009, 45, 98-107. [CrossRef]

12. Rashid, G.; Ali, M.H. Fault ride through capability improvement of DFIG based wind farm by fuzzy logic controlled parallel resonance fault current limiter. Electr. Power Syst. Res. 2017, 146, 1-8. [CrossRef]

13. Hossain, M.K.; Ali, M.H. Transient stability augmentation of PV/DFIG/SG-based hybrid power system by parallel-resonance bridge fault current limiter. Electr. Power Syst. Res. 2016, 130, 89-102. [CrossRef]

14. Sadi, M.A.H.; Ali, M.H. A comprehensive analysis of transient stability enhancement methods of electric power system. In Proceedings of the 2015 North American Power Symposium (NAPS), Charlotte, NC, USA, 4-6 October 2015; pp. 1-6.

15. Radmanesh, H.; Fathi, S.H.; Gharehpetian, G.; Heidary, A. Bridge-type solid-state fault current limiter based on AC/DC reactor. IEEE Trans. Power Deliv. 2015, 31, 200-209. [CrossRef]

16. Shen, H.; Mei, F.; Zheng, J.; Sha, H.; She, C. Three-Phase Saturated-Core Fault Current Limiter. Energies 2018, 11, 3471. [CrossRef]

17. Alam, M.; Abido, M.; El-Amin, I. Fault current limiters in power systems: A Comprehensive Review. Energies 2018, 11, 1025. [CrossRef]

18. Yang, Q.; Le Blond, S.; Liang, F.; Yuan, W.; Zhang, M.; Li, J. Design and application of superconducting fault current limiter in a multiterminal HVDC system. IEEE Trans. Appl. Supercond. 2017, 27, 1-5. [CrossRef]

19. Zou, Z.C.; Xiao, X.Y.; Liu, Y.F.; Zhang, Y.; Wang, Y.H. Integrated protection of DFIG-based wind turbine with a resistive-type SFCL under symmetrical and asymmetrical faults. IEEE Trans. Appl. Supercond. 2016, 26, 1-5. [CrossRef]

20. Ngamroo, I.; Karaipoom, T. Improving low-voltage ride-through performance and alleviating power fluctuation of DFIG wind turbine in DC microgrid by optimal SMES with fault current limiting function. IEEE Trans. Appl. Supercond. 2014, 24, 1-5. [CrossRef] 
21. Lee, H.J.; Lim, S.H.; Kim, J.C. Application of a Superconducting Fault Current Limiter to Enhance the Low-Voltage Ride-Through Capability of Wind Turbine Generators. Energies 2019, 12, 1478. [CrossRef]

22. Zou, Z.C.; Chen, X.Y.; Li, C.S.; Xiao, X.Y.; Zhang, Y. Conceptual design and evaluation of a resistive-type SFCL for efficient fault ride through in a DFIG. IEEE Trans. Appl. Supercond. 2015, 26, 1-9. [CrossRef]

23. Rasolonjanahary, J.; Sturgess, J.; Chong, E.; Baker, A.; Sasse, C. Design and construction of a magnetic fault current limiter. In Proceedings of the 3rd IET International Conference on Power Electronics, Machines and Drives-PEMD, Dublin, Ireland, 4-6 April 2006; IET: London, UK, 2006; pp. 681-685.

24. Qu, L.; Zeng, R.; Yu, Z.; Li, G. Design and test of a magnetic saturation-type fault current limiter. J. Eng. 2019, 2019, 2974-2979. [CrossRef]

25. Yuan, J.; Zhong, Y.; Lei, Y.; Tian, C.; Guan, W.; Gao, Y.; Muramatsu, K.; Chen, B. A novel hybrid saturated core fault current limiter topology considering permanent magnet stability and performance. IEEE Trans. Magn. 2017, 53, 1-4. [CrossRef]

26. Tseng, H.T.; Jiang, W.Z.; Lai, J.S. A Modified Bridge Switch-Type Flux-Coupling Nonsuperconducting Fault Current Limiter for Suppression of Fault Transients. IEEE Trans. Power Deliv. 2018, 33, 2624-2633. [CrossRef]

27. Rashid, G.; Ali, M.H. Transient stability enhancement of doubly fed induction machine-based wind generator by bridge-type fault current limiter. IEEE Trans. Energy Convers. 2015, 30, 939-947. [CrossRef]

28. Sadi, M.A.H.; Ali, M.H. A fuzzy logic controlled bridge type fault current limiter for transient stability augmentation of multi-machine power system. IEEE Trans. Power Syst. 2015, 31, 602-611. [CrossRef]

29. Rashid, G.; Ali, M.H. Application of parallel resonance fault current limiter for fault ride through capability augmentation of DFIG based wind farm. In Proceedings of the IEEE/PES Transmission and Distribution Conference and Exposition (T\&D), Dallas, TX, USA, 2-5 May 2016; pp. 1-5.

30. Firouzi, M.; Gharehpetian, G.B. LVRT performance enhancement of DFIG-based wind farms by capacitive bridge-type fault current limiter. IEEE Trans. Sustain. Energy 2017, 9, 1118-1125. [CrossRef]

31. Kartijkolaie, H.S.; Radmehr, M.; Firouzi, M. LVRT capability enhancement of DFIG-based wind farms by using capacitive DC reactor-type fault current limiter. Int. J. Electr. Power Energy Syst. 2018, 102, 287-295. [CrossRef]

32. Naderi, S.; Davari, P.; Zhou, D.; Negnevitsky, M.; Blaabjerg, F. A Review on Fault Current Limiting Devices to Enhance the Fault Ride-Through Capability of the Doubly-Fed Induction Generator Based Wind Turbine. Appl. Sci. 2018, 8, 2059. [CrossRef]

33. Rashid, G.; Ali, M.H. A modified bridge-type fault current limiter for fault ride-through capacity enhancement of fixed speed wind generator. IEEE Trans. Energy Convers. 2014, 29, 527-534.

34. Causebrook, A.; Atkinson, D.J.; Jack, A.G. Fault ride-through of large wind farms using series dynamic braking resistors. IEEE Trans. Power Syst. 2007, 22, 966-975. [CrossRef]

35. Soliman, M.A.; Hasanien, H.M.; Azazi, H.Z.; El-Kholy, E.E.; Mahmoud, S.A. Hybrid ANFIS-GA-based control scheme for performance enhancement of a grid-connected wind generator. IET Renew. Power Gener. 2018, 12, 832-843. [CrossRef]

36. Rashid, G.; Ali, M.H. Nonlinear control-based modified BFCL for LVRT capacity enhancement of DFIG-based wind farm. IEEE Trans. Energy Convers. 2016, 32, 284-295. [CrossRef]

37. Le, V.; Li, X.; Li, Y.; Dong, T.; Le, C. An innovative control strategy to improve the fault ride-through capability of DFIGs based on wind energy conversion systems. Energies 2016, 9, 69. [CrossRef]

38. Okedu, K.E.; Muyeen, S.; Takahashi, R.; Tamura, J. Wind farms fault ride through using DFIG with new protection scheme. IEEE Trans. Sustain. Energy 2012, 3, 242-254. [CrossRef]

39. Lopez, J.; Sanchis, P.; Roboam, X.; Marroyo, L. Dynamic behavior of the doubly fed induction generator during three-phase voltage dips. IEEE Trans. Energy Convers. 2007, 22, 709-717. [CrossRef]

40. Sadi, M.A.H.; Ali, M.H. Lyapunov Function Controlled Parallel Resonance Fault Current Limiter for Transient Stability Enhancement of Power System. In Proceedings of the 2018 North American Power Symposium (NAPS), Fargo, ND, USA, 9-11 September 2018; pp. 1-6.

41. Sadi, M.A.H.; Ali, M.H. Maintaining Distribution Protective Relay Coordination By Sliding Mode Control Based Bridge Type Fault Current Limiter. In Proceedings of the 2019 IEEE Power \& Energy Society General Meeting (PESGM), Atlanta, GA, USA, 4-8 August 2019; pp. 1-5. 
42. Yan, S.; Ren, L.; Wang, Z.; Yang, Z.; Xu, Y.; Chen, L.; Yu, B.; Tang, Y.; Liang, S. Simulation analysis and experimental tests of a small-scale flux-coupling type superconducting fault current limiter. IEEE Trans. Appl. Supercond. 2016, 27, 1-5. [CrossRef]

43. Pei, X.; Smith, A.C.; Barnes, M. Superconducting fault current limiters for HVDC systems. Energy Procedia 2015, 80, 47-55. [CrossRef]

(C) 2020 by the authors. Licensee MDPI, Basel, Switzerland. This article is an open access article distributed under the terms and conditions of the Creative Commons Attribution (CC BY) license (http:/ / creativecommons.org/licenses/by/4.0/). 